\title{
Basal forebrain cholinergic neurons selectively drive coordinated motor learning in mice
}

Yue $\mathrm{Li}^{1}$, Edmund Hollis II $^{1,2 *}$

${ }^{1}$ Burke Neurological Institute, White Plains, NY, United States. ${ }^{2}$ Feil Family Brain and Mind Research Institute, Weill Cornell Medicine, New York, NY, United States.

*For correspondence: edh3001@med.cornell.edu (EH)

\begin{abstract}
Motor control requires precise temporal and spatial encoding across distinct motor centers that is refined through the repetition of learning. The coordination of circuit refinement across motor regions requires modulatory input to shape circuit activity. Here we identify a role for the basocortical cholinergic pathway in the acquisition of a coordinated motor skill in mice. Targeted depletion of basal forebrain cholinergic neurons results in significant impairments in training on the rotarod task of coordinated movement. Cholinergic neuromodulation is required during training sessions as chemogenetic inactivation of cholinergic neurons also impairs task acquisition. Rotarod learning drives coordinated refinement of corticostriatal neurons arising in both medial prefrontal cortex (mPFC) and motor cortex, and we have found that cholinergic input to both motor regions is required for task acquisition. Critically, the effects of cholinergic neuromodulation are restricted to the acquisition stage, as depletion of basal forebrain cholinergic neurons after learning does not affect task execution. Our results indicate a critical role for cholinergic neuromodulation of distant cortical motor centers during coordinated motor learning.
\end{abstract}




\section{Introduction}

The learning of coordinated motor behavior requires synchronization across distinct motor centers throughout the central nervous system. Coordinated task acquisition drives dynamic patterns of neuronal activity and synaptic plasticity in the cortex and striatum. Within the striatum, there is a progressive shift in regional influence, with dorsomedial striatum critical in early stages, followed by a shift to dorsolateral striatum later in task acquisition (Yin et al., 2009). Coherence develops within corticostriatal motor networks with precise timing of primary motor cortex (M1) and dorsolateral striatum (DLS) activity in support of motor performance across learning (Koralek et al., 2013; Koralek et al., 2012; Lemke et al., 2019). During accelerating rotarod training, associative medial prefrontal cortex connections to dorsomedial striatum (mPFC-DMS) are recruited concurrently alongside motor circuits projecting from primary motor cortex to dorsolateral striatum (Kupferschmidt et al., 2017). Early in learning, mPFC-DMS and M1-DLS circuits show parallel activation, while these patterns diverge as animals master the motor skill (Kupferschmidt et al., 2017). In rodents that have mastered learned motor skills, there is a dissociation between M1 and movement execution. On simple tasks, M1 appears to be dispensable as complete ablation does not alter trained movements (Kawai et al., 2015); whereas, more complex motor tasks have demonstrated that M1 activity is required for the appropriate execution of fine motor control (Lemke et al., 2019). Modulated motor control arises during motor training with M1 and DLS contributing to gross movement, while only M1 inactivation disrupts fine movements (Lemke et al., 2019). Neuromodulation of M1, but not mPFC, via cholinergic input from basal forebrain has been shown to be a key mechanism that supports the cortical plasticity that occurs during skilled motor learning in the rat (Conner et al., 2010). We have assessed the role of cholinergic input to M1 and mPFC in coordinated motor control. 
The basal forebrain is one of the principal sites of acetylcholine synthesis in the brain.

Cholinergic projections arising from basal forebrain subregions innervate distinct targets, modulating functions varying from motor control, sensory and perceptual coding, attention, memory, to anxiety (Boskovic et al., 2019; Zaborszky et al., 2018). Cholinergic neurons in the nucleus basalis of Meynert (NBM) have widespread projections to the cerebral cortex, while neurons in the diagonal band of Broca (DBB) and substantia innominata (SI) send projections to the prefrontal cortex (Boskovic et al., 2019). Basal forebrain cholinergic neurons are consistently activated at the onset of movement (Harrison et al., 2016), potentially synchronizing distant cortical motor centers. Neuromodulation requires temporal precision to modulate target area dynamics and synaptic plasticity, and reinforce cognitive and reward behaviors (Gil et al., 1997; Kruglikov and Rudy, 2008; Metherate et al., 1992).

Cholinergic signaling throughout cortical sensory and motor regions acts to modulate network properties and enhance glutamatergic signaling, driving long-lasting changes in synaptic strength (Rasmusson, 2000). In the auditory cortex, muscarinic acetylcholine signaling plays an instructional role in receptive field plasticity (Bakin and Weinberger, 1996; Kilgard and Merzenich, 1998; Miasnikov et al., 2001), while in visual cortex, cholinergic innervation is required for experience-dependent visual plasticity during the critical period (Bear and Singer, 1986). Following critical period closure, visual cortex plasticity is limited in adulthood by the prototoxin lynx1, an allosteric regulator of nicotinic acetylcholine receptors that reduces acetylcholine sensitivity (Miwa et al., 2006). Knockout of lynx1 extends ocular dominance plasticity beyond the critical period into adulthood (Morishita et al., 2010). Within M1, the maturation of motor representations, or maps, depends upon basal forebrain cholinergic input (Ramanathan et al., 2015). In rats, basal forebrain cholinergic input to M1 has been found to support the plasticity of these motor maps as well as the remodeling of corticospinal neuron dendrite morphology (Conner et al., 2003; Conner et al., 2010; Wang et al., 2011). Across 
sensory modalities, the basal forebrain cholinergic system acts as a rapid and precisely timed reinforcement signal to support fast cortical activation and plasticity in associative learning (Hangya et al., 2015; Hanson et al., 2021; Liu et al., 2015).

In the present study, we demonstrate a key role for cholinergic basal forebrain neurons in the acquisition of coordinated motor behavior. We used targeted toxin-mediated and genetic depletion of NBM/SI cholinergic neurons and found that the acquisition of accelerating rotarod behavior was impaired. Disrupting the temporal activation of NBM/SI cholinergic neurons similarly impaired task acquisition. As rotarod task acquisition requires coordinated activity across distant motor centers, we tested whether selectively targeting cholinergic innervation of mPFC or primary motor cortex affected performance and found that cholinergic input to both areas was required for coordinated motor learning. The effects of disrupting basal forebrain cholinergic input to the cortex was specific to the acquisition phase of rotarod behavior as we found that cholinergic depletion after training elicited no effect on task execution. In contrast to previous findings in the rat (Conner et al., 2003), we found no effect of cholinergic depletion on the learning of a skilled forelimb task. Our findings demonstrate a critical role for cholinergic neuromodulation in coordinated motor performance.

\section{Materials and Methods}

\section{Mice}

All animal experiments and procedures were approved by the Weill Cornell Medicine Institutional Animal Care and Use Committee. All mice were housed on a 12-hour light/dark cycle from 6 am to $6 \mathrm{pm}$ at $25^{\circ} \mathrm{C}$ with free access to food and water. For skilled pellet reach behavior, animals were calorie restricted to $80-90 \%$ of their free-feeding bodyweight. Male and female C57BL/6 animals (8-12 weeks old) were purchased from Jackson Laboratory. ChAT-Cre mice were originally obtained from Jackson Laboratory and bred in-house. In our study, hemizygous ChAT-Cre mice were used, which were achieved by back-crossing the 
homozygous ChAT-Cre line to C57BL/6 mice. In some experiments, hemizygous ChAT-

Cre::Ai14 mice were used. This mouse line expresses tdTomato in ChAT-positive neurons.

\section{Cholinergic neuron ablation by p75-saporin}

Twenty-eight ten-week-old C57BL/6J mice were anesthetized with $4 \%$ isoflurane, maintained during surgery with $1.5-3 \%$ isoflurane, and had body temperature maintained at $37^{\circ} \mathrm{C}$ using a SomnoSuite small animal anesthesia system (Kent Scientific). Subcutaneous (SQ) injection of buprenorphine $(0.1 \mathrm{mg} / \mathrm{kg})$ and meloxicam $(2 \mathrm{mg} / \mathrm{kg})$ was given immediately following anesthesia. For global ablation of cholinergic neurons in NBM/SI basal forebrain, anti-p75 conjugated saporin (p75-saporin) or IgG-saporin control ( $n=8 /$ group, Advanced Targeting Systems) was diluted to final concentration of $0.4 \mathrm{mg} / \mathrm{ml}$ in normal saline. Saporin solution (150 $\mathrm{nl} / \mathrm{site}$ ) was bilaterally injected into NBM/SI areas at a rate of $120 \mathrm{nl} / \mathrm{min}$ using a glass micropipette filled with mineral oil and attached to a programmable Nanoject III (Drummond Scientific). NBM/SI injection sites: 1) A/P $-0.22 \mathrm{~mm}, \mathrm{M} / \mathrm{L} \pm 1.25 \mathrm{~mm}, \mathrm{D} / \mathrm{V}-4.7 \mathrm{~mm}$; 2) A/P -0.7 $\mathrm{mm}, \mathrm{M} / \mathrm{L} \pm 1.75 \mathrm{~mm}$, and $\mathrm{D} / \mathrm{V}-4.7 \mathrm{~mm}$. Following each injection, the pipette was held in place for an additional 4 min to prevent backflow. Mice were allowed to recover from surgery for 2 weeks prior to behavioral experiments.

In order to selectively ablate basal forebrain cholinergic neurons projecting to specific cortical regions, focal injections were performed in the target areas. IgG-saporin or p75-saporin was diluted to a final concentration of $0.08 \mathrm{mg} / \mathrm{ml}$ in normal saline. Saporin solution was bilaterally injected into $\mathrm{mPFC}$, motor cortex, or visual cortex at a rate of $40 \mathrm{nl} / \mathrm{min}$. The following injection volume and coordinates of injection sites were used: mPFC site 1) $200 \mathrm{nl}$ at A/P $+2.3 \mathrm{~mm}, \mathrm{M} / \mathrm{L}$ $\pm 0.3 \mathrm{~mm}, \mathrm{D} / \mathrm{N}-1.5 \mathrm{~mm}$; mPFC site 2) $200 \mathrm{nl}$ at A/P $+1.5 \mathrm{~mm}, \mathrm{M} / \mathrm{L} \pm 0.3 \mathrm{~mm}, \mathrm{D} / \mathrm{V}-2.0 \mathrm{~mm}$; motor cortex site 1) $200 \mathrm{nl}$ at A/P $+1.5 \mathrm{~mm}, \mathrm{M} / \mathrm{L} \pm 1.3 \mathrm{~mm}, \mathrm{D} / \mathrm{V}-0.6 \mathrm{~mm}$; motor cortex site 2) 200 $\mathrm{nl}$ at $\mathrm{A} / \mathrm{P}+0.5 \mathrm{~mm}, \mathrm{M} / \mathrm{L} \pm 1.5 \mathrm{~mm}, \mathrm{D} / \mathrm{V}-0.6 \mathrm{~mm}$; motor cortex site 3) $200 \mathrm{nl}$ at A/P $-0.5 \mathrm{~mm}, \mathrm{M} / \mathrm{L}$ 
$\pm 1.2 \mathrm{~mm}, \mathrm{D} / \mathrm{V}-0.6 \mathrm{~mm}$; visual cortex site 1) $250 \mathrm{nl}$ at A/P $-2.8 \mathrm{~mm}, \mathrm{M} / \mathrm{L} \pm 2.3 \mathrm{~mm}, \mathrm{D} / \mathrm{V}-0.6 \mathrm{~mm}$; visual cortex site 2) $250 \mathrm{nl}$ at $\mathrm{A} / \mathrm{P}-3.8 \mathrm{~mm}, \mathrm{M} / \mathrm{L} \pm 2.3 \mathrm{~mm}, \mathrm{D} / \mathrm{V}-0.6 \mathrm{~mm}$.

\section{Cholinergic neuron ablation by diphtheria toxin}

A targeted genetic approach was used to ablate basal forebrain cholinergic neurons. Sixteen eight-week-old transgenic mice expressing Cre recombinase behind the ChAT promoter crossed with Ai14 Rosa-LSL-tdTomato in the C57BL/6J background (ChAT-Cre::Ai14) were transduced with AAV encoding Cre recombinase-dependent diphtheria toxin receptor and the fluorescent reporter eYFP (AAV-DJ/8-EF1A-FLEX -DTR-P2A-EYFP) by bilateral injection into NBM/SI at a rate of $120 \mathrm{nl} / \mathrm{min}$ (Herman et al., 2016). AAV expressing only Cre-dependent eYFP fluorescent protein (AAV-DJ/8-EF1A-FLEX-P2A-EYFP) was used as control. NBM/SI was injected with $350 \mathrm{nl}$ of virus $\left[8.73 \times 10^{12} \mathrm{VG} / \mathrm{ml}\right]$ at the following coordinates: site 1) A/P $-0.1 \mathrm{~mm}$, $\mathrm{M} / \mathrm{L} \pm 1.25 \mathrm{~mm}, \mathrm{D} / \mathrm{V}-4.7 \mathrm{~mm}$; site 2) A/P $-0.45 \mathrm{~mm}, \mathrm{M} / \mathrm{L} \pm 1.5 \mathrm{~mm}, \mathrm{D} / \mathrm{V}-4.7 \mathrm{~mm}$; site 3) A/P -0.8 $\mathrm{mm}, \mathrm{M} / \mathrm{L} \pm 1.75 \mathrm{~mm}, \mathrm{D} / \mathrm{V}-4.7 \mathrm{~mm}$. The pipette was held in place for an additional $4 \mathrm{~min}$. Two weeks after viral injection, diphtheria toxin (DT, $100 \mu \mathrm{g} / \mathrm{kg}$, Sigma D0564) was intraperitoneally injected to ablate cholinergic neurons expressing DTR. Two weeks later, behavioral tests were performed.

\section{Chemogenetic modulation of cholinergic neuron activity}

In order to test the role of cholinergic neuron activity during coordinated motor performance, the designer receptor exclusively activated by designer drug (DREADD) system was used. Twenty hemizygous ChAT-Cre mice were bilaterally injected with Cre-dependent inhibitory DREADD fused with mCherry reporter AAV8-hsyn-DIO-hM4Di-mCherry (1×1013 VG/ml; Addgene, 44362) or control virus (AAV8-hsyn-DIO-mCherry) $\left(1 \times 10^{13} \mathrm{VG} / \mathrm{ml}\right.$; Addgene, 50459) into $3 \mathrm{NBM} / \mathrm{SI}$ sites (350 nl/site) as with AAV-DTR. After 3 weeks to allow for viral expression, the DREADD ligand JHU37160 (J60, Hello Bio) was administered via intraperitoneal injection at a dose of $1.0 \mathrm{mg} / \mathrm{kg}$ 30 minutes prior to rotarod training. 


\section{Accelerating rotarod test}

Mice were habituated on the rotarod (Ugo Basile, 47650) at a speed of $4 \mathrm{rpm}$ for $60 \mathrm{~s}$ before testing. For each trial, the rotarod accelerated from 5 to 60 rpm over $300 \mathrm{~s}$. In SAP and DT experiments, mice were trained for 3 trials/day over 3 days with a 30 min interval between trials. For DREADD experiments, mice were tested 30 min after IP injection of DREADD ligand, 3 trials/day over 3 days without an interval between trials. In alternate rotarod training, mice were habituated at $4 \mathrm{rpm}$ for $60 \mathrm{~s}$ on a different rotarod (Med Associates, Inc. ENV-577M), with trials accelerating from 4 to 40 rpm over $5 \mathrm{~min}$. The latency to fall after the onset of acceleration during each trial was recorded for each mouse. Individual trials were stopped, and the duration was recorded if mice could not run with consecutive rotations or failed to stay on the rotarod.

\section{Recessed forelimb reach task}

Mice were food restricted to $80-90 \%$ of their free-feeding bodyweight before training. An acrylic behavior box with three slots $(7 \mathrm{~mm}$ wide) on the left, middle, and right sides of the front wall was used to train the mice. A recessed hole ( $3 \mathrm{~mm}$ wide, $2 \mathrm{~mm}$ deep) at $12 \mathrm{~mm}$ from the inside wall of the box was used to hold a $20 \mathrm{mg}$ flavored food pellet (Bioserv, F05301). The dominant forelimb for reaching was identified during one session of pellet reaching. Once the dominant forelimb was determined, it was trained over a total of 14 daily sessions consisting of 25 trials each. Mice often become sated and less likely to perform skilled reach after 25 trials. A trial was counted as a success if the mouse successfully grasped, retrieved, and ate the pellet. Only trials with pellet contact were counted. The success rate was defined as the percentage of trials with successful retrieval and eating.

\section{Nestlet shredding}

$1.2 \mathrm{~g}$ nestlets were placed into each test cage and the mass of remaining intact nestlet was measured at several time points over a one-week period. 


\section{Open field test}

Mice were placed in a chamber $(\mathrm{L} \times \mathrm{W} \times \mathrm{H}: 30 \mathrm{~cm} \times 22.5 \mathrm{~cm} \times 25 \mathrm{~cm})$ and allowed to explore for 5 min. Behavior was recorded from the top of the chamber at $48 \mathrm{fps}(\mathrm{GoPro}, \mathrm{HERO}+$ ) and analyzed by MatLab software (Autotyping15.04 source code) (Patel et al., 2014). Thigmotaxis was defined as the percentage of time that mice spent within two inches of the arena walls.

\section{Wire hanging test}

Mice were individually placed on a wire mesh grid. Once the animal grasped the grid with all four paws and appeared stable, the mesh was inverted and placed atop an open chamber. The duration that the mice were able to hang from the grid was recorded. A soft blanket was placed at the bottom of the chamber to avoid animal injury. Each animal was tested 3 times and the longest duration was used as the animal's latency to fall.

\section{Retrograde NBM/SI labeling}

Retrograde tracing was performed in 8-week-old C57BL/6J mice $(n=4)$ in order to label basal forebrain neurons projecting to specific cortical areas. Alexa Fluor 488, 555, or 647 conjugated Cholera Toxin B subunit (CTB) (1\% wt/vol, Molecular Probes) was bilaterally injected to mPFC (A/P +1.9 mm, M/L $\pm 0.3 \mathrm{~mm}, \mathrm{D} / \mathrm{V}-1.5 \mathrm{~mm})$, motor cortex $(+0.5 \mathrm{~mm}, \pm 1.5 \mathrm{~mm},-0.6 \mathrm{~mm})$, or visual cortex (-3.3 mm, $\pm 2.3 \mathrm{~mm},-0.6 \mathrm{~mm})$, respectively. A burr hole was drilled over each corresponding area and $100 \mathrm{nl}$ tracer was injected at each site at a rate of $40 \mathrm{nl} / \mathrm{min}$. To prevent backflow, the pipette was left in the brain for 5 minutes after injection. Mice were sacrificed 1 week later. Transverse brain sections were cut coronally at $40 \mu \mathrm{m}$ of thickness. ChAT immunostaining was performed to label cholinergic neurons. Some sections were counterstained with DAPI. Sections containing injection sites were imaged at 10x on a Leica SP8 confocal microscopy with parameters adjusted based on the intensity of expression and background fluorescence (tile scan). Images containing cholinergic neurons were acquired using 10x objective. 


\section{Histology}

Mice were anesthetized with ketamine/xylazine cocktail [150 mg/kg; $15 \mathrm{mg} / \mathrm{kg}]$ and transcardially perfused with ice-cold PBS followed by $4 \%$ paraformaldehyde (PFA). Brains were harvested and post-fixed in $4 \%$ PFA overnight at $4^{\circ} \mathrm{C}$, cryoprotected by immersion in $30 \%$ sucrose in $0.1 \mathrm{M}$ PBS for 2 days, and transversely cryosectioned (40 $\mu \mathrm{m}$ thick) using a Leica cryostat. Free floating sections were permeabilized with $0.3 \%$ Triton $\mathrm{X}-100$ in PBS for 30 min at room temperature. After blocking with $10 \%$ donkey serum, sections were incubated with primary antibodies for 2 days at $4^{\circ} \mathrm{C}$. Primary antibodies used: goat anti-ChAT (1:100, Millipore, AB144P), rabbit anti-p75 (1:100, Advanced Targeting Systems, AB-N01AP), rabbit anti-GFP (1:1500, Invitrogen, A6455), rabbit anti-DsRed antibodies (1:3000, Takara, 632496). Sections were washed three times in PBS, followed by incubation with fluorescently conjugated secondary antibodies (1:200, Jackson ImmunoResearch) for 1.5 hours at room temperature. Nuclei were labeled with a 10-minute incubation with DAPI [1 $\mu \mathrm{g} / \mathrm{ml}]$ in PBS. Images were acquired on a Leica SP8 confocal microscope with 10x or 20x objectives under constant imaging parameters. Total CTB-labeled NBM/SI neurons in serial sections were manually counted.

\section{Statistics}

Rotarod, skilled pellet reach, and nestlet shredding behavior tests were analyzed using two-way repeated measures analysis of variance (ANOVA) with post-hoc Sidak's comparison test using GraphPad Prism 9.0. Two-tailed t-tests were used to compare differences between two groups. Two-way ANOVA with post hoc Dunnett's multiple comparisons test was used to compare cholinergic fibers among different groups. All behavior and analysis were performed in a doubleblinded manner. For all figures, ${ }^{*} P<0.05 ;{ }^{* *} P<0.01 ;{ }^{* *} P<0.001$. 


\section{Results}

\section{Ablation of basal forebrain cholinergic neurons impairs coordinated motor training}

In order to ablate basal forebrain cholinergic neurons, we injected C57BL/6J mice bilaterally with anti-p75 conjugated saporin (p75-SAP) into the nucleus basalis of Meynert (NBM) and substantia innominata (SI); control mice were injected with IgG-conjugated saporin (IgG-SAP) (Figure 1A). p75-SAP targets cholinergic neurons in the basal forebrain as they selectively express the low-affinity nerve growth factor p75NTR receptor. p75-SAP infusion resulted in nearly complete loss of NBM/SI cholinergic neurons (Figure 1B,C; $n=8$, two-tailed t-test, $P<$ 0.001). Motor coordination was tested using an accelerating rotarod. Mice were trained over 9 trials starting at $5 \mathrm{rpm}$ with a constant acceleration over 5 minutes to $60 \mathrm{rpm}$. Both male and female mice injected with p75-SAP exhibited worse performance on accelerating rotarod compared to $\operatorname{lgG}$ injected controls, with significantly shorter latency to fall (Figure 1D,E; $n=8$, two-way repeated measures ANOVA, $P=0.004)$. These results confirmed the findings from a pilot study in which mice trained under alternate conditions (4-40 rpm over $5 \mathrm{~min}$ ) on a different rotarod showed impaired performance following depletion of basal forebrain cholinergic neurons by p75-SAP injection, relative to IgG-SAP controls (Figure 1 -figure supplement 1 ; $n=6$, twoway ANOVA, $P<0.001)$. In addition to rotarod deficits, animals with cholinergic neuron ablation showed a reduction in repetitive, nestlet-shredding behavior. Control mice quickly tear up nestlet bedding material placed in their cages while p75-SAP injected mice showed dramatically reduced nesting behavior as determined by measuring the mass of nestlets over 7 days (Figure 1F,G; two-way ANOVA, $P<0.003)$.

Mice were also trained to perform a recessed version of the single pellet reach task over 2 weeks. The single pellet reach task is frequently used in rat models to study motor learning (Bova et al., 2019; Chen et al., 2014; Zemmar et al., 2015); however, many mice fail to show an improvement on the standard pellet reach task, exhibiting an essentially flat learning curve 
across training (Chen et al., 2014). We therefore used a modified, recessed version of the skilled reach task in which mice have to retrieve a food pellet from a concave depression (Figure $1 \mathrm{H}$ ). On the standard task, the initial success rate was $27 \pm 5 \%$, while after two weeks of training this had only increased to $37 \pm 4 \%$ (Figure 1 -figure supplement $2 \mathrm{~A}, \mathrm{~B}$ ). The resulting increase was not statistically significant (paired t-test, $P=0.15$ ). Separate mice trained on the recessed forelimb reach task had a lower initial success rate at $17 \pm 3 \%$, but a more consistent improvement, increasing to $41 \pm 3 \%$ with training (paired t-test, $P<0.0001$ ). $43 \%$ of mice trained on the standard forelimb reach task failed to improve by more than $15 \%$ over the course of two weeks (Figure 1-figure supplement 2C), while $93 \%$ of mice trained on the recessed forelimb reach task demonstrated improvements with training. This recessed version of the single pellet reach task allowed us to assess skilled motor learning in our study. We found that p75-SAP injection did not impair the learning of the recessed forelimb reach task, as both groups exhibited a similar improvement in performance over the course of training (Figure 1I).

We tested the overall health of mice after cholinergic ablation. At two weeks after saporin injection, mice injected with p75-SAP exhibited a slight but significant decrease in the body mass (Figure 1-figure supplement 3A; $n=8$, paired t-test, $P=0.002$ ). Overall animal strength was unaffected as determined using a wire hanging test. Both groups showed a similar time to fall, regardless of gender (Figure 1-figure supplement 3B,C). General activity was tested in an open field (Figure 1-figure supplement 3D). p75-SAP injected mice exhibited a reduced total walking distance compared to IgG injected controls (Figure 1-figure supplement 3E, two-tailed t-test, $P=0.042)$. As mice navigated the open field, they largely remained close to the walls (thigmotaxis), indicative of a normal level of anxiety. No difference in thigmotaxis was observed between groups (Figure 1-figure supplement 3F). 


\section{Genetic lesion of basal forebrain cholinergic neurons impairs coordinated motor training}

We next used a targeted genetic approach to deplete basal forebrain cholinergic neurons.

ChAT-Cre::Ai14 mice were bilaterally injected into NBM/SI with AAV encoding the diphtheria toxin receptor in a Cre-dependent manner (AAV/DJ8-FLEX-DTR-EYFP). Control mice were injected with AAV expressing only Cre-dependent EYFP fluorescent reporter (Figure 2A).

Diphtheria toxin (DT) injection ablated nearly all cholinergic neurons in the NBM and SI areas in mice transduced with AAV-FLEX-DTR-EYFP (Figure 2B,C and Figure 2-figure supplement 1A). Motor cortex and mPFC received strong cholinergic innervation from NBM/SI areas, as exhibited in mice injected with control virus (Figure 2D). Two weeks after DT injection, AAVDIO-DTR-EYFP mice showed a mild, but significant decrease in body mass (Figure 2-figure supplement $1 \mathrm{~B} ; n=8$, paired t-test, $P<0.001$ ). DT-injected control animals showed no reduction in body mass. Similar to the effects of p75-SAP NBM/SI lesion, DT injection into AAVDIO-DTR-EYFP transduced ChAT-Cre::Ai14 mice resulted in severely impaired performance on the accelerating rotarod (5-60 rpm over $5 \mathrm{~min}$ ) (Figure $2 \mathrm{E}, \mathrm{F} ; n=8$, ANOVA, $P=0.001$ ). Furthermore, ChAT-Cre::Ai14 mice transduced with DTR virus exhibited dramatically reduced nestlet shredding behavior after DT treatment (Figure 2G; ANOVA, $P<0.001$ ). DT injection had no effect on the learning of the recessed forelimb reach task (Figure 2-figure supplement 1CE).

\section{Chemogenetic silencing of cholinergic neurons impairs coordinated motor training}

In order to test the role of cholinergic neuron activity during the acquisition of coordinated motor behavior, the designer receptor exclusively activated by designer drug (DREADD) system was used. ChAT-Cre mice were bilaterally injected into NBM/SI with Cre-dependent inhibitory DREADD AAV-DIO-hM4Di-mCherry or control virus (AAV-DIO-mCherry) (Figure 3A). After 3 weeks to allow for viral expression (Figure 3B), rotarod training was performed 30 min after intraperitoneal injection of the DREADD ligand JHU37160 (J60, $1 \mathrm{mg} / \mathrm{kg})$. A total of 9 trials were 
performed on the accelerating rotarod (5-60 rpm over $5 \mathrm{~min}$ ). Inactivation of cholinergic neurons during behavior significantly impaired rotarod performance (Figure 3C,D; $n=10$, ANOVA, $P=$ 0.0033).

\section{Cholinergic projections to both motor cortex and MPFC are required for coordinated motor training}

As basal forebrain cholinergic neurons project extensively throughout the cortex, we selectively targeted cholinergic inputs to distinct cortical areas in order to determine the target locus of acetylcholine action during coordinated motor learning. We injected p75-SAP directly into motor areas required for coordinated motor learning, mPFC and motor cortex, as well as into visual cortex, which is not anticipated to be involved in the task (Figure 4 A,B and Figure 4-figure supplement 1). Control animals were injected with IgG-SAP into mPFC, motor, or visual cortices. IgG-SAP injection into different targets had no effect on rotarod behavior and data from these animals were pooled. Two weeks after SAP injections, mice were trained on the accelerating rotarod. Depletion of cholinergic input to both mPFC and motor cortex produced significant deficits in rotarod performance, compared to control lgG-SAP injected animals (Figure 4C and Figure 4-figure supplement 2A; ANOVA, $P=0.0011$ ). Visual cortex injection of p75-SAP had mild but not significant effects on behavior. Unlike global depletion of NBM/SI cholinergic neurons, there was no obvious effect of local ablation on nestlet shredding behavior (Figure 4-figure supplement 2B). Mice with targeted ablation of cholinergic neurons were then trained on skilled behavior. Similar to global ablation of NBM/SI cholinergic neurons, targetspecific ablation of cholinergic neurons had no effect on training of the recessed forelimb reach task (Figure 4-figure supplement 2C). These data indicate that cholinergic basal forebrain neurons regulate motor coordination through modulation of both primary and associative motor circuits (Figure 4D). 
In order to determine if collateral branches of NBM/SI neurons innervate the anatomically isolated regions tested above, we injected unique fluorescently conjugated retrograde tracer CTB into mPFC (488 nm), motor cortex (555 nm), and visual cortex (647 nm, Figure 5A,B).

Overall, $58 \%$ of labeled neurons in basal forebrain were ChAT-positive. The majority of CTBlabeled basal forebrain input to motor and visual cortices were from cholinergic neurons at $71.2 \pm 6.1$ and $57.2 \pm 2.0 \%$, respectively. In mPFC, the percentage of cholinergic neurons was $49.4 \pm 1.4 \%$ (Figure 5C). Retrogradely labeled, non-cholinergic, basal forebrain neurons include GABAergic or glutamatergic neurons (Gritti et al., 2003; Henny and Jones, 2008; Kim et al., 2015). The majority of cholinergic neurons $(84.4 \pm 2.0 \%)$ were labeled with a single CTB tracer, indicating that there was no overlap in their axonal projections within the labeled regions (Figure $5 \mathrm{D}, \mathrm{E})$. Although the sites of retrograde tracer injection were distal to each other, we did observe overlapping labeling of a small population of basal forebrain cholinergic neurons. Double-labeled neurons projecting to $\mathrm{mPFC}$ and motor cortex represented $4.1 \pm 1.4 \%$ of NBM/SI cholinergic neurons, motor and visual cortices $3.6 \pm 1.4 \%$, and mPFC and visual cortex

$5.9 \pm 2.4 \%$. Cholinergic neurons labeled by three colors of CTB were observed rarely $(2.1 \pm 1.5 \%)$. The shared innervation may, at least in part, explain the mild effects of cholinergic input to visual cortex on rotarod training.

\section{Basal forebrain cholinergic neurons are not required for execution of previously trained coordinated motor behavior}

To determine whether basal forebrain cholinergic neurons are simply required for the execution rotarod behavior, rather than for the learning of the coordinated motor task, we trained intact mice prior to NBM/SI cholinergic neuron ablation. Mice were first trained on the accelerating rotarod for 9 trials and then randomly assigned to treatment with either p75-SAP or control lgGSAP injection into NBM/SI. Two weeks later, the retention of trained rotarod behavior was tested (Figure 6A). Execution of the previously trained rotarod behavior was unaffected in both groups, 
with comparable fall latencies before and after SAP injection (Figure 6B,C). Next, we used a genetic approach to test the effects of cholinergic ablation on coordinated motor task retention. ChAT-Cre transgenic mice were injected with AAV-DIO-DTR-EYFP or control virus. Ten days later, mice were trained through 9 trials on the accelerating rotarod prior to intraperitoneal injection of DT to ablate cholinergic neurons (Figure 6D). DTR and EYFP control expressing mice exhibited similar rotarod performance both before and after DT injection (Figure 6E,F). These results demonstrate that basal forebrain cholinergic signaling is not needed for the execution of previously learned coordinated motor behavior.

\section{Discussion}

Our findings in this study demonstrate that basal forebrain cholinergic neurons exert control over coordinated motor learning. Ablation or inhibition of these cholinergic neurons impairs coordinated task acquisition but does not affect execution of previously learned coordinated behavior. These findings are important as the release of acetylcholine rapidly modulates neuronal excitability, circuit dynamics, and cortical coding; all processes required for processing complex sensory information, cognition, and attention (Ballinger et al., 2016; Goard and Dan, 2009; Metherate et al., 1992; Villano et al., 2017). Baso-cortical cholinergic pathways are critical neuromodulators of auditory, visual, olfactory, and somatosensory perception. In primary auditory cortex, pairing electrical stimulation of NBM with a specific auditory stimulus leads to circuit remodeling (Bakin and Weinberger, 1996; Kilgard and Merzenich, 1998). Within S1, increased cholinergic signaling suppresses slow spontaneous activity and drives the depolarization of layer 2/3 neurons during whisking (Eggermann et al., 2014). Modulating the activity of basal forebrain cholinergic neurons alters visual and olfactory discrimination capabilities (Goard and Dan, 2009; Ma and Luo, 2012; Pinto et al., 2013). In addition to sensory coding, the cholinergic input to primary visual cortex is also required for the acquisition, but not the expression, of reward timing in the primary visual cortex (Chubykin et al., 2013; Liu et al., 
2015). Cholinergic neurons also disinhibit layer 1 interneurons in auditory cortex and mediate associative fear learning (Letzkus et al., 2011). Our study raises the possibility that baso-cortical cholinergic input rapidly modulates the active state of motor networks during coordinated motor learning.

In addition to mPFC and sensorimotor cortex, learned motor movements rely on the coordinated output of thalamus, basal ganglia, cerebellum, and brainstem motor centers. Training drives a shift in the contributions of cortical and subcortical motor circuits, with an early instructional role for motor cortex supporting the development of independent movement initiation by the basal ganglia (Kawai et al., 2015). Indeed, the contribution of the motor cortex to learned movements appears to decline over time with continued training (Hwang et al., 2019). We demonstrate clearly that basal forebrain cholinergic signaling is critical for the early instructional phase of coordinated motor learning. As we found that cholinergic inputs to both mPFC and motor cortex are required for coordinated motor acquisition, it is likely that cholinergic neuromodulation plays a critical role in the coactivation of mPFC-DMS and M1-DLS circuits during early stage rotarod learning (Kupferschmidt et al., 2017). As training progresses and instructional input from cortical projections is no longer driving experience-dependent refinement of striatal motor circuits (Wolff et al., 2019), cholinergic neuromodulation of cortical motor centers is no longer required. This is supported by our findings that ablation of cholinergic neurons after rotarod training elicited no effect on performance of the previously trained task.

Basal forebrain cholinergic input to $\mathrm{M} 1$ has been shown to be a key modulator of the cortical plasticity mechanisms that underlie skilled forelimb reach training in rats (Conner et al., 2003). Several lines of evidence implicate cholinergic neuromodulation in the large-scale cortical changes that occur following injury or motor learning in other species (Conner et al., 2005; Juliano et al., 1991). While we did not assess cortical reorganization in our studies, our data showed that skilled motor learning on a recessed version of the single pellet reach task was 
unaffected following cholinergic ablation in mice. These results may owe to species differences in the refinement of cortical mechanisms, or perhaps to differences in the acetylcholinedependent development of cortical motor representations (Ramanathan et al., 2015). In fact, mice often fail to demonstrate the learning curves exhibited by rats in the standard single pellet reach task used in earlier studies. Typically a large percentage of mice will exhibit a high proficiency on the task on the first days of training and show no subsequent improvement, or even a decline in performance over time (Figure 1-figure supplement 2) (Chen et al., 2014). The modified, recessed forelimb reach task appears to be more difficult for mice, and reliably results in performance improvements with training. Another critical difference observed was that our studies showed a role for mPFC cholinergic inputs in coordinated motor task acquisition, while p75-SAP targeting of mPFC had no effect on forelimb reach training in rats (Conner et al., 2010). This is consistent with the coordination of activity across MPFC and M1 that others have shown in rotarod training (Kupferschmidt et al., 2017). Whether there are specific basal forebrain circuits, or other neuromodulatory mechanisms, in mice that differentially regulate the acquisition of coordinated and skilled tasks is a critical question that requires further study.

Beyond the effects on cortical plasticity, acetylcholine signaling plays a key role in cognitive processes by mediating attention (Sarter and Lustig, 2019; Thiele and Bellgrove, 2018). Within the visual cortex, attention drives increased firing rates via acetylcholine signaling through muscarinic receptors in non-human primates (Herrero et al., 2008). Within humans, numerous studies have suggested a critical role for external focus of attention in skilled motor learning (Lewthwaite and Wulf, 2017; Lohse et al., 2014; Song, 2019; Wulf, 2013). External focus of attention is tightly linked to practice variability and task improvements that occur through movement revision during motor learning (Chua et al., 2019). Meanwhile, divided attention impairs task learning by reducing movement adaptations across trials (Song, 2019). The effects of external focus of attention are robust, driving motor learning both in neurotypical individuals 
as well as in individuals with intellectual disabilities (Chiviacowsky et al., 2013). The central role of attention in the acquisition of motor skills supports the idea that cognitive components are indispensable in the adjustment of motor output and training-induced improvements in motor performance (Gallivan et al., 2018; McDougle et al., 2016).

As we observed a critical role for cholinergic input to mPFC in coordinated motor learning, it may be that disruption of circuit level mediators of attention impair motor learning. Prefrontal cortex in primates mediates top-down attentional control over sensory systems through direct input to inferotemporal cortex (Baluch and Itti, 2011; Miller and Buschman, 2013; Petrides, 2000). Within mPFC, attention drives increases in synchronous activity of fast-spiking parvalbumin inhibitory interneurons and increased gamma oscillations (Kim et al., 2016). Acetylcholine signaling through muscarinic receptors in mPFC is required for cue-mediated increases in gamma oscillations (Howe et al., 2017; Parikh et al., 2007). On a cued discrimination task, optogenetic activation of basal forebrain cholinergic neurons has been shown to enhance sensitivity to short duration cues, but also to increase incorrect attempts in the absence of cues (Gritton et al., 2016). In contrast, silencing of cholinergic inputs impairs cue detection (Gritton et al., 2016). A role for cholinergic modulation of attention during coordinated motor learning may, in part, explain motor deficits in neurological disorders otherwise characterized by cognitive dysfunction. While the hallmarks of neurodegenerative disorders such as Alzheimer's disease (AD) are cognitive impairments, the neuropathological effects on attention in AD (Miloyan et al., 2013) may explain pre-clinical motor decline in AD individuals (Albers et al., 2015) and coordinated motor learning impairments in AD mouse models (O'Leary et al., 2018). Our results may provide insight into the relevance of motor and sensory dysfunction and pre-clinical AD prognosis. 


\section{Acknowledgements}

We thank Amanda Bernstein for assisting in behavioral tests and data analysis, Anne

Marchildon for animal breeding and genotyping, and Sydney Agger for illustrations. We also

thank Rachel Garn for early contributions to the manuscript. We acknowledge IDDRC

Neuroconnectivity Core at Baylor College of Medicine and the viral core at Boston Children's

Hospital for producing DTR virus. pAAV-hSyn-DIO-hM4Di-mCherry was generated by Bryan

Roth (Addgene plasmid \# 44362). This work was supported by Burke Foundation and the

National Institutes of Health Common Fund DP2 NS106663 to EH, New York State Department

of Health SCIRB postdoctoral fellowship (C32633GG) to YL.

\section{Author contributions}

$\mathrm{YL}$ and $\mathrm{EH}$ designed the study; $\mathrm{YL}$ performed the experiments. $\mathrm{YL}$ and $\mathrm{EH}$ wrote the manuscript.

\section{Competing interests}

The authors declare that no competing interests exist. 


\section{References}

Albers, M.W., Gilmore, G.C., Kaye, J., Murphy, C., Wingfield, A., Bennett, D.A., Boxer, A.L., Buchman, A.S., Cruickshanks, K.J., Devanand, D.P., et al. (2015). At the interface of sensory and motor dysfunctions and Alzheimer's disease. Alzheimers Dement 11, 70-98.

Bakin, J.S., and Weinberger, N.M. (1996). Induction of a physiological memory in the cerebral cortex by stimulation of the nucleus basalis. Proc Natl Acad Sci U S A 93, 11219-11224.

Ballinger, E.C., Ananth, M., Talmage, D.A., and Role, L.W. (2016). Basal Forebrain Cholinergic Circuits and Signaling in Cognition and Cognitive Decline. Neuron 91, 1199-1218.

Baluch, F., and Itti, L. (2011). Mechanisms of top-down attention. Trends Neurosci 34, 210-224.

Bear, M.F., and Singer, W. (1986). Modulation of visual cortical plasticity by acetylcholine and noradrenaline. Nature 320, 172-176.

Boskovic, Z., Meier, S., Wang, Y., Milne, M.R., Onraet, T., Tedoldi, A., and Coulson, E.J. (2019). Regulation of cholinergic basal forebrain development, connectivity, and function by neurotrophin receptors. Neuronal Signaling 3, NS20180066.

Bova, A., Kernodle, K., Mulligan, K., and Leventhal, D. (2019). Automated Rat Single-Pellet Reaching with 3-Dimensional Reconstruction of Paw and Digit Trajectories. Journal of visualized experiments : JoVE.

Chandler, D., and Waterhouse, B. (2012). Evidence for Broad Versus Segregated Projections from Cholinergic and Noradrenergic Nuclei to Functionally and Anatomically Discrete Subregions of Prefrontal Cortex. Frontiers in Behavioral Neuroscience 6.

Chen, C.C., Gilmore, A., and Zuo, Y. (2014). Study motor skill learning by single-pellet reaching tasks in mice. J Vis Exp.

Chiviacowsky, S., Wulf, G., and Avila, L.T. (2013). An external focus of attention enhances motor learning in children with intellectual disabilities. Journal of intellectual disability research : JIDR $57,627-634$. 
Chua, L.-K., Dimapilis, M.K., Iwatsuki, T., Abdollahipour, R., Lewthwaite, R., and Wulf, G. (2019). Practice variability promotes an external focus of attention and enhances motor skill learning. Human Movement Science 64, 307-319.

Chubykin, A.A., Roach, E.B., Bear, M.F., and Shuler, M.G. (2013). A cholinergic mechanism for reward timing within primary visual cortex. Neuron 77, 723-735.

Conner, J.M., Chiba, A.A., and Tuszynski, M.H. (2005). The basal forebrain cholinergic system is essential for cortical plasticity and functional recovery following brain injury. Neuron 46, 173-179. Conner, J.M., Culberson, A., Packowski, C., Chiba, A.A., and Tuszynski, M.H. (2003). Lesions of the Basal forebrain cholinergic system impair task acquisition and abolish cortical plasticity associated with motor skill learning. Neuron 38, 819-829.

Conner, J.M., Kulczycki, M., and Tuszynski, M.H. (2010). Unique contributions of distinct cholinergic projections to motor cortical plasticity and learning. Cereb Cortex 20, 2739-2748.

Eggermann, E., Kremer, Y., Crochet, S., and Petersen, C.C.H. (2014). Cholinergic signals in mouse barrel cortex during active whisker sensing. Cell Rep 9, 1654-1660.

Gallivan, J.P., Chapman, C.S., Wolpert, D.M., and Flanagan, J.R. (2018). Decision-making in sensorimotor control. Nature reviews Neuroscience 19, 519-534.

Gil, Z., Connors, B.W., and Amitai, Y. (1997). Differential regulation of neocortical synapses by neuromodulators and activity. Neuron 19, 679-686.

Goard, M., and Dan, Y. (2009). Basal forebrain activation enhances cortical coding of natural scenes. Nat Neurosci 12, 1444-1449.

Gritti, I., Manns, I.D., Mainville, L., and Jones, B.E. (2003). Parvalbumin, calbindin, or calretinin in cortically projecting and GABAergic, cholinergic, or glutamatergic basal forebrain neurons of the rat. J Comp Neurol 458, 11-31.

Gritton, H.J., Howe, W.M., Mallory, C.S., Hetrick, V.L., Berke, J.D., and Sarter, M. (2016). Cortical cholinergic signaling controls the detection of cues. Proceedings of the National Academy of Sciences of the United States of America 113, E1089-E1097. 
Hangya, B., Ranade, S.P., Lorenc, M., and Kepecs, A. (2015). Central Cholinergic Neurons Are Rapidly Recruited by Reinforcement Feedback. Cell 162, 1155-1168.

Hanson, E., Brandel-Ankrapp, K.L., and Arenkiel, B.R. (2021). Dynamic Cholinergic Tone in the Basal Forebrain Reflects Reward-Seeking and Reinforcement During Olfactory Behavior. Front Cell Neurosci 15, 635837.

Harrison, T.C., Pinto, L., Brock, J.R., and Dan, Y. (2016). Calcium Imaging of Basal Forebrain Activity during Innate and Learned Behaviors. Front Neural Circuits 10, 36.

Henny, P., and Jones, B.E. (2008). Projections from basal forebrain to prefrontal cortex comprise cholinergic, GABAergic and glutamatergic inputs to pyramidal cells or interneurons. Eur $\mathrm{J}$ Neurosci 27, 654-670.

Herman, A.M., Ortiz-Guzman, J., Kochukov, M., Herman, I., Quast, K.B., Patel, J.M., Tepe, B., Carlson, J.C., Ung, K., Selever, J., et al. (2016). A cholinergic basal forebrain feeding circuit modulates appetite suppression. Nature 538, 253-256.

Herrero, J.L., Roberts, M.J., Delicato, L.S., Gieselmann, M.A., Dayan, P., and Thiele, A. (2008). Acetylcholine contributes through muscarinic receptors to attentional modulation in V1. Nature $454,1110-1114$

Howe, W.M., Gritton, H.J., Lusk, N.A., Roberts, E.A., Hetrick, V.L., Berke, J.D., and Sarter, M. (2017). Acetylcholine Release in Prefrontal Cortex Promotes Gamma Oscillations and ThetaGamma Coupling during Cue Detection. The Journal of Neuroscience 37, 3215-3230.

Hwang, E.J., Dahlen, J.E., Hu, Y.Y., Aguilar, K., Yu, B., Mukundan, M., Mitani, A., and Komiyama, T. (2019). Disengagement of motor cortex from movement control during long-term learning. Science advances 5, eaay0001-eaay0001.

Juliano, S.L., Ma, W., and Eslin, D. (1991). Cholinergic depletion prevents expansion of topographic maps in somatosensory cortex. Proceedings of the National Academy of Sciences of the United States of America 88, 780-784. 
Kawai, R., Markman, T., Poddar, R., Ko, R., Fantana, Antoniu L., Dhawale, Ashesh K., Kampff, Adam R., and Ölveczky, Bence P. (2015). Motor cortex is required for learning but not for executing a motor skill. Neuron $86,800-812$.

Kilgard, M.P., and Merzenich, M.M. (1998). Cortical map reorganization enabled by nucleus basalis activity. Science $279,1714-1718$.

Kim, H., Ahrlund-Richter, S., Wang, X., Deisseroth, K., and Carlen, M. (2016). Prefrontal Parvalbumin Neurons in Control of Attention. Cell 164, 208-218.

Kim, T., Thankachan, S., McKenna, J.T., McNally, J.M., Yang, C., Choi, J.H., Chen, L., Kocsis, B., Deisseroth, K., Strecker, R.E., et al. (2015). Cortically projecting basal forebrain parvalbumin neurons regulate cortical gamma band oscillations. Proc Natl Acad Sci U S A 112, 3535-3540.

Koralek, A.C., Costa, R.M., and Carmena, J.M. (2013). Temporally precise cell-specific coherence develops in corticostriatal networks during learning. Neuron 79, 865-872.

Koralek, A.C., Jin, X., Long, J.D., 2nd, Costa, R.M., and Carmena, J.M. (2012). Corticostriatal plasticity is necessary for learning intentional neuroprosthetic skills. Nature 483, 331-335.

Kruglikov, I., and Rudy, B. (2008). Perisomatic GABA release and thalamocortical integration onto neocortical excitatory cells are regulated by neuromodulators. Neuron 58, 911-924.

Kupferschmidt, D.A., Juczewski, K., Cui, G., Johnson, K.A., and Lovinger, D.M. (2017). Parallel, but Dissociable, Processing in Discrete Corticostriatal Inputs Encodes Skill Learning. Neuron 96, 476-489 e475.

Lemke, S.M., Ramanathan, D.S., Guo, L., Won, S.J., and Ganguly, K. (2019). Emergent modular neural control drives coordinated motor actions. Nature Neuroscience 22, 1122-1131.

Letzkus, J.J., Wolff, S.B., Meyer, E.M., Tovote, P., Courtin, J., Herry, C., and Luthi, A. (2011). A disinhibitory microcircuit for associative fear learning in the auditory cortex. Nature 480, 331-335. Lewthwaite, R., and Wulf, G. (2017). Optimizing motivation and attention for motor performance and learning. Current opinion in psychology 16, 38-42. 
Liu, C.H., Coleman, J.E., Davoudi, H., Zhang, K., and Hussain Shuler, M.G. (2015). Selective activation of a putative reinforcement signal conditions cued interval timing in primary visual cortex. Current biology : CB 25, 1551-1561.

Lohse, K.R., Jones, M., Healy, A.F., and Sherwood, D.E. (2014). The role of attention in motor control. Journal of experimental psychology General 143, 930-948.

Ma, M., and Luo, M. (2012). Optogenetic activation of basal forebrain cholinergic neurons modulates neuronal excitability and sensory responses in the main olfactory bulb. J Neurosci 32 , $10105-10116$.

McDougle, S.D., Ivry, R.B., and Taylor, J.A. (2016). Taking Aim at the Cognitive Side of Learning in Sensorimotor Adaptation Tasks. Trends in cognitive sciences 20, 535-544.

Metherate, R., Cox, C.L., and Ashe, J.H. (1992). Cellular bases of neocortical activation: modulation of neural oscillations by the nucleus basalis and endogenous acetylcholine. J Neurosci 12, 4701-4711.

Miasnikov, A.A., McLin, D., 3rd, and Weinberger, N.M. (2001). Muscarinic dependence of nucleus basalis induced conditioned receptive field plasticity. Neuroreport 12, 1537-1542.

Miller, E.K., and Buschman, T.J. (2013). Cortical circuits for the control of attention. Current opinion in neurobiology 23, 216-222.

Miloyan, B.H., Razani, J., Larco, A., Avila, J., and Chung, J. (2013). Aspects of Attention Predict Real-World Task Performance in Alzheimer's Disease. Appl Neuropsychol Adult 20, 203-210.

Miwa, J.M., Stevens, T.R., King, S.L., Caldarone, B.J., Ibanez-Tallon, I., Xiao, C., Fitzsimonds, R.M., Pavlides, C., Lester, H.A., Picciotto, M.R., et al. (2006). The Prototoxin lynx1 Acts on Nicotinic Acetylcholine Receptors to Balance Neuronal Activity and Survival In Vivo. Neuron 51, 587-600.

Morishita, H., Miwa, J.M., Heintz, N., and Hensch, T.K. (2010). Lynx1, a cholinergic brake, limits plasticity in adult visual cortex. Science 330, 1238-1240. 
O'Leary, T.P., Robertson, A., Chipman, P.H., Rafuse, V.F., and Brown, R.E. (2018). Motor function deficits in the 12 month-old female 5xFAD mouse model of Alzheimer's disease. Behav Brain Res 337, 256-263.

Parikh, V., Kozak, R., Martinez, V., and Sarter, M. (2007). Prefrontal acetylcholine release controls cue detection on multiple timescales. Neuron 56, 141-154.

Patel, T.P., Gullotti, D.M., Hernandez, P., O'Brien, W.T., Capehart, B.P., Morrison, B., 3rd, Bass, C., Eberwine, J.E., Abel, T., and Meaney, D.F. (2014). An open-source toolbox for automated phenotyping of mice in behavioral tasks. Frontiers in behavioral neuroscience 8, 349.

Petrides, M. (2000). Dissociable Roles of Mid-Dorsolateral Prefrontal and Anterior Inferotemporal Cortex in Visual Working Memory. The Journal of Neuroscience 20, 7496-7503.

Pinto, L., Goard, M.J., Estandian, D., Xu, M., Kwan, A.C., Lee, S.H., Harrison, T.C., Feng, G., and Dan, Y. (2013). Fast modulation of visual perception by basal forebrain cholinergic neurons. Nat Neurosci 16, 1857-1863.

Ramanathan, D.S., Conner, J.M., Anilkumar, A.A., and Tuszynski, M.H. (2015). Cholinergic systems are essential for late-stage maturation and refinement of motor cortical circuits. $\mathrm{J}$ Neurophysiol 113, 1585-1597.

Rasmusson, D.D. (2000). The role of acetylcholine in cortical synaptic plasticity. Behav Brain Res $115,205-218$.

Sarter, M., and Lustig, C. (2019). Cholinergic double duty: cue detection and attentional control. Current opinion in psychology 29, 102-107.

Song, J.H. (2019). The role of attention in motor control and learning. Current opinion in psychology 29, 261-265.

Thiele, A., and Bellgrove, M.A. (2018). Neuromodulation of Attention. Neuron 97, 769-785.

Villano, I., Messina, A., Valenzano, A., Moscatelli, F., Esposito, T., Monda, V., Esposito, M., Precenzano, F., Carotenuto, M., Viggiano, A., et al. (2017). Basal Forebrain Cholinergic System and Orexin Neurons: Effects on Attention. Frontiers in behavioral neuroscience 11, 10. 
Wang, L., Conner, J.M., Rickert, J., and Tuszynski, M.H. (2011). Structural plasticity within highly specific neuronal populations identifies a unique parcellation of motor learning in the adult brain. Proceedings of the National Academy of Sciences 108, 2545-2550.

Wolff, S.B.E., Ko, R., and Ölveczky, B.P. (2019). Distinct roles for motor cortical and thalamic inputs to striatum during motor learning and execution. bioRxiv, 825810 .

Wu, H., Williams, J., and Nathans, J. (2014). Complete morphologies of basal forebrain cholinergic neurons in the mouse. eLife 3, e02444.

Wulf, G. (2013). Attentional focus and motor learning: a review of 15 years. Int Rev Sport Exer P $6,77-104$.

Yin, H.H., Mulcare, S.P., Hilario, M.R., Clouse, E., Holloway, T., Davis, M.I., Hansson, A.C., Lovinger, D.M., and Costa, R.M.K., 2017 \#67859\} (2009). Dynamic reorganization of striatal circuits during the acquisition and consolidation of a skill. Nat Neurosci 12, 333-341.

Zaborszky, L., Gombkoto, P., Varsanyi, P., Gielow, M.R., Poe, G., Role, L.W., Ananth, M., Rajebhosale, P., Talmage, D.A., Hasselmo, M.E., et al. (2018). Specific Basal Forebrain-Cortical Cholinergic Circuits Coordinate Cognitive Operations. J Neurosci 38, 9446-9458.

Zemmar, A., Kast, B., Lussi, K., Luft, A.R., and Schwab, M.E. (2015). Acquisition of a Highprecision Skilled Forelimb Reaching Task in Rats. Journal of visualized experiments : JoVE, e53010. 


\section{Figure Legends}

\section{Figure 1. Pharmacological ablation of basal forebrain cholinergic neurons impairs} coordinated motor learning.

(A) NBM/SI basal forebrain cholinergic neuron targeting with anti-p75 conjugated saporin or control IgG-saporin. (B) NBM/SI cholinergic neurons following IgG-SAP or p75-SAP injection (scale bar $=200 \mu \mathrm{m}$ ). (C) Quantification of ChAT immunostained neurons in NBM/SI basal forebrain in animals with IgG-SAP (control) or p75-SAP injection (two-tailed t-test, ${ }^{* * *} P<0.001$ ). (D) Ablation of cholinergic neurons by p75-SAP severely impaired rotarod training performance (repeated measures ANOVA, $P=0.0004, F(1,14)=21.31)$. $(E)$ p75-SAP effects were independent of sex. (F) Nestlet shredding behavior in female and male mice injected with lgGSAP (control) or p75-SAP. (G) Quantification of remaining, intact nestlets over time ( $n$ is number of cages, repeated measures ANOVA, $P=0.0003, F(1,8)=35.79)$. $(\mathrm{H})$ Illustration of the recessed forelimb reach task. (I) Learning of the recessed forelimb reach task was unimpaired following p75-SAP injection (repeated measures ANOVA, $P>0.05, \mathrm{~F}(1,22)=0.2983$ ). Data presented as mean \pm s.e.m., $n$ in parentheses is number of mice unless otherwise indicated.

Figure 2. Genetic depletion of cholinergic neurons impairs coordinated motor learning. (A) Timeline outlining genetic ablation of cholinergic neurons in hemizygous ChAT-Cre::Ai14 mice followed by behavior tests (top panel). NBM/SI basal forebrain cholinergic neuron transduction with AAV-DTR or control EYFP. (B) NBM/SI cholinergic neurons expressing tdTomato in mice injected with AAV-FLEX-EYFP (control) or AAV-FLEX-DTR-EYFP (scale bar $=200 \mu \mathrm{m})$. (C) Quantification of EYFP or tdTomato positive neurons in NBM/SI basal forebrain (two-tailed t-test, $\left.{ }^{* *} P<0.001\right)$. (D) EYFP-labeled cholinergic fibers in motor cortex and mPFC after AAV-FLEX-EYFP transduction of cholinergic neurons in ChAT-Cre mice (scale bar $=100$ $\mu \mathrm{m}) .(\mathrm{E})$ Genetic ablation of cholinergic neurons in basal forebrain severely impaired performance on rotarod training (repeated-measures ANOVA, $P=0.001, \mathrm{~F}(1,14)=17.30)$. $(\mathrm{F})$ 
Rotarod latencies averaged for 3 trials each day (repeated measures ANOVA with post-hoc

Sidak's comparison test, $\left.{ }^{* *} P<0.01\right)$. (G) Quantification of remaining, intact nestlets over time $(n$ is number of cages, repeated measures ANOVA, $P<0.0001, F(1,8)=117.4)$. Data presented as mean \pm s.e.m., $n$ in parentheses is number of mice unless otherwise indicated.

\section{Figure 3. Chemogenetic silencing of cholinergic neurons impairs coordinated motor} performance.

(A) NBM/SI basal forebrain cholinergic neuron transduction with AAV-DIO-hM4Di-mCherry in hemizygous ChAT-Cre mice. (B) hM4Di-mCherry fusion protein expression in ChAT positive neurons (scale bar $=200 \mu \mathrm{m})$. (C) JHU37160 delivered 30 minutes prior to behavior severely impaired performance on rotarod training in mice expressing hM4Di in NBM/SI cholinergic neurons (repeated-measures ANOVA, $P=0.0033, F(1,18)=11.44)$. (D) Rotarod latencies averaged for 3 trials each day (repeated measures ANOVA with post hoc Sidak's comparison test, $\left.{ }^{*} P<0.05,{ }^{* *} P<0.01\right)$. Data presented as mean \pm s.e.m..

Figure 4. Cholinergic inputs to both MPFC and motor cortex are required for coordinated motor training.

(A) Cholinergic innervation in mPFC, motor cortex (MCx), and visual cortex (VCx) after selective targeting with IgG-SAP or p75-SAP (scale bar $=20 \mu \mathrm{m}$ ). (B) Quantification of p75 positive cholinergic fibers in MPFC, MCx, and VCx in response to selective ablation of cholinergic inputs (two-way ANOVA with post hoc Dunnett's multiple comparisons test, ${ }^{*} P<0.05,{ }^{* *} P<0.01$ ). (C) Depletion of cholinergic inputs to either mPFC, MCx, or both MPFC and MCx significantly impaired performance on rotarod behavior training. Depletion of cholinergic input to visual cortex (VCx) had a partial impact on rotarod performance (repeated-measures ANOVA, $P=$ $0.0011, F(4,50)=5.382$.). (D) Schematic illustrating cholinergic innervation of distant motor centers involved in coordinated motor learning. Data presented as mean \pm s.e.m.. 
Figure 5. Retrograde labeling of NBM/SI cholinergic projections to cortex.

(A) Illustration of retrograde tracing strategy: CTB conjugated to Alexa Fluor 488, 555, or 647 was bilaterally injected to mPFC (cyan), motor cortex (red), or visual cortex (purple), respectively. (B) CTB injection sites: mPFC (cyan), motor cortex (red), and visual cortex (purple). Sections were stained with DAPI (gray) (scale bar = $1 \mathrm{~mm}$ ). (C) Quantification of cholinergic and non-cholinergic neurons projecting to cerebral cortices. (D) Retrograde labeling of NBM/SI with CTB conjugates. Neurons 1, 2 and 3 projected to one of these three cortices. Neuron 4 projected to mPFC and motor cortex. Neuron 5 projected to mPFC and visual cortex. Neuron 6 is non-cholinergic (scale bar $=40 \mu \mathrm{m}$ ). (E) Quantification of total CTB-labeled cholinergic NBM/SI neurons.

Figure 6. Basal forebrain cholinergic neurons are not required for execution of previously learned coordinated motor behavior.

(A) Timeline outlining experimental details of cholinergic ablation by p75-SAP following rotarod training. Retention testing was performed 2 weeks after saporin injection. (B) Pharmacological ablation of cholinergic neurons did not affect the performance on the previously learned rotarod behavior (paired t-tests, $P>0.05$ for both groups). (C) The ratio of latencies to fall before and after cholinergic ablation (Post/Pre) (two-tailed t-test, $P=0.34$ ). (D) Timeline outlining experimental details of cholinergic ablation by AAV-DTR following rotarod training. Rotarod retention testing was performed 2 weeks after DT injection. (E) Genetic ablation of cholinergic neurons did not affect the performance on the previously learned rotarod behavior (paired ttests, $P>0.05$ for both groups). (F) The ratio of latencies to fall before and after DT-induced cholinergic ablation (Post/Pre) (two-tailed t-test, $p=0.24$ ). Data presented as mean \pm s.e.m..

\section{Figure 1-figure supplement 1 . Accelerating rotarod tests.}


(A) In an alternate rotarod training paradigm, C57BL/6J mice were trained on a Med Associates, Inc. ENV-577M rotarod with trials accelerating from 4 to $40 \mathrm{rpm}$ over $5 \mathrm{~min}$ followed by an additional $5 \mathrm{~min}$ at $40 \mathrm{rpm}$. (B) Ugo Basile 47650 rotarod used in main figures; the training paradigm was continuous acceleration from 5 to $60 \mathrm{rpm}$ over $5 \mathrm{~min}$. (C) Ablation of cholinergic neurons by p75-SAP severely impaired alternate rotarod training performance (repeatedmeasures ANOVA, $P<0.0001, \mathrm{~F}(1,10)=42.74)$. (D) p75-SAP effects were independent of sex. Data presented as mean \pm s.e.m..

\section{Figure 1-figure supplement 2. Mice exhibit more consistent learning on the recessed}

\section{forelimb reach task.}

(A) Illustration depicting the standard skilled pellet reach behavior. (B) Successful retrieval rate significantly improves over 2 weeks of behavioral training on the recessed version compared to the standard task. (C) The majority of mice exhibit learning over the course of training on the recessed version of the task (14/15), in contrast to the standard task (4/7). Data presented as mean \pm s.e.m..

\section{Figure 1-figure supplement 3. General effects of cholinergic ablation by p75-SAP.}

(A) Mice injected with p75-SAP had a slight but significant decrease in body mass (paired t-test, ${ }^{* *} p<0.01$ ). (B) Grid hanging test. (C) Animal strength was similar between treatment groups (two-tailed t-test, $P=0.70$ ). (D) Representative sample of the open field test showing walking trace of one mouse (top panel); outer red rectangle marked the boundary of walking space. The distance between 2 rectangles is 2 inches. Heat map of walking trace (bottom panel). (E) Total walking distance was shorter in mice injected with p75-SAP (two-tailed t-test, $P=0.042$ ). (F) Thigmotaxis was similar between treatment groups Data presented as mean \pm s.e.m.. 


\section{Figure 2-figure supplement 1. DT-induced ablation of DTR-expressing cholinergic} neurons.

(A) Transverse section from a ChAT-Cre::Ai14 mouse transduced with control AAV-FLEX-EYFP (left) or AAV-FLEX-DTR-EYFP (right) showing targeted depletion of NBM/SI cholinergic neurons at 2 weeks after DT injection (scale bar $=1 \mathrm{~mm}$ ). (B) DTR expression in NBM/SI cholinergic neurons leads to a slight but significant decrease in the body mass at 2 weeks after DT injection (paired t-tests, $\left.{ }^{* *} P<0.01,{ }^{* * *} P<0.001\right)$. (C-E) In a subset of experiments, hemizygous ChATCre mice were co-injected with AAV8-syn-FLEX-DTR and AAV2-syn-FLEX-EGFP. Two weeks later, mice were injected with DT. Confocal images showed EGFP expression in mice with or without transduction of DTR virus (C). Scale $=200 \mu \mathrm{m}$. (D) Quantification of the number of EGFP positive neurons in basal forebrain of animals injected with AAV8-DTR as compared to control animals (unpaired t-test, ${ }^{* * *} P<0.001$ ). (E) Genetic ablation of cholinergic neurons did not impair learning of recessed forelimb reach task (repeated-measures ANOVA, $P=0.1429, \mathrm{~F}$ $(1,11)=2.49)$. Data presented as mean \pm SEM.

Figure 4-figure supplement 1. Depletion of cholinergic innervation in distinct cortical areas.

p75 immunostaining of cholinergic fibers in mPFC, MCx, and VCx from mice with local injection of p75-SAP or control lgG-SAP (scale bar $=20 \mu \mathrm{m}$ ).

\section{Figure 4-figure supplement 2. General effects of depletion of cholinergic inputs to} specific cortical areas.

(A) Rotarod latencies averaged for 3 trials each day (repeated measures ANOVA with post hoc Sidak's comparison test. $\left.{ }^{*} P<0.05,{ }^{* *} P<0.01,{ }^{* * *} P<0.001\right)$. (B,C) Depletion of cholinergic inputs to mPFC, motor cortex (MCx), or visual cortex (VCx) has no effect on nestlet shredding behavior (B) or recessed forelimb reach task (C). 
A

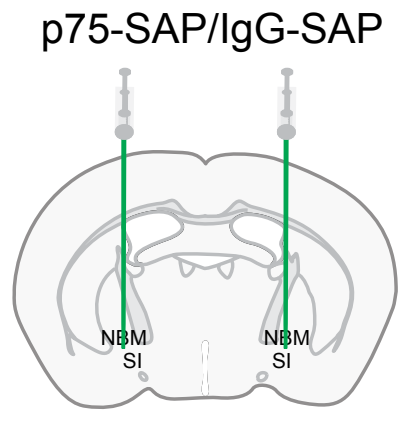

D

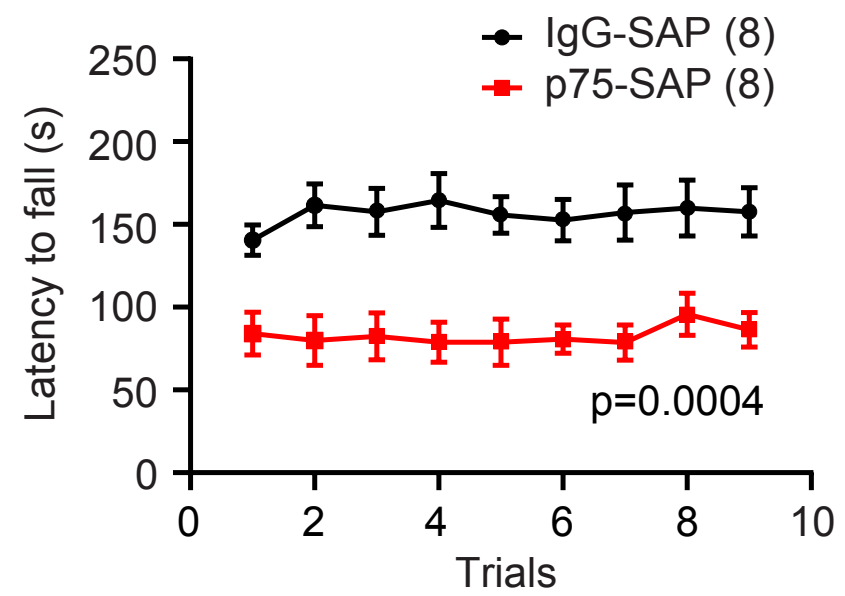

$\mathbf{F}$

G
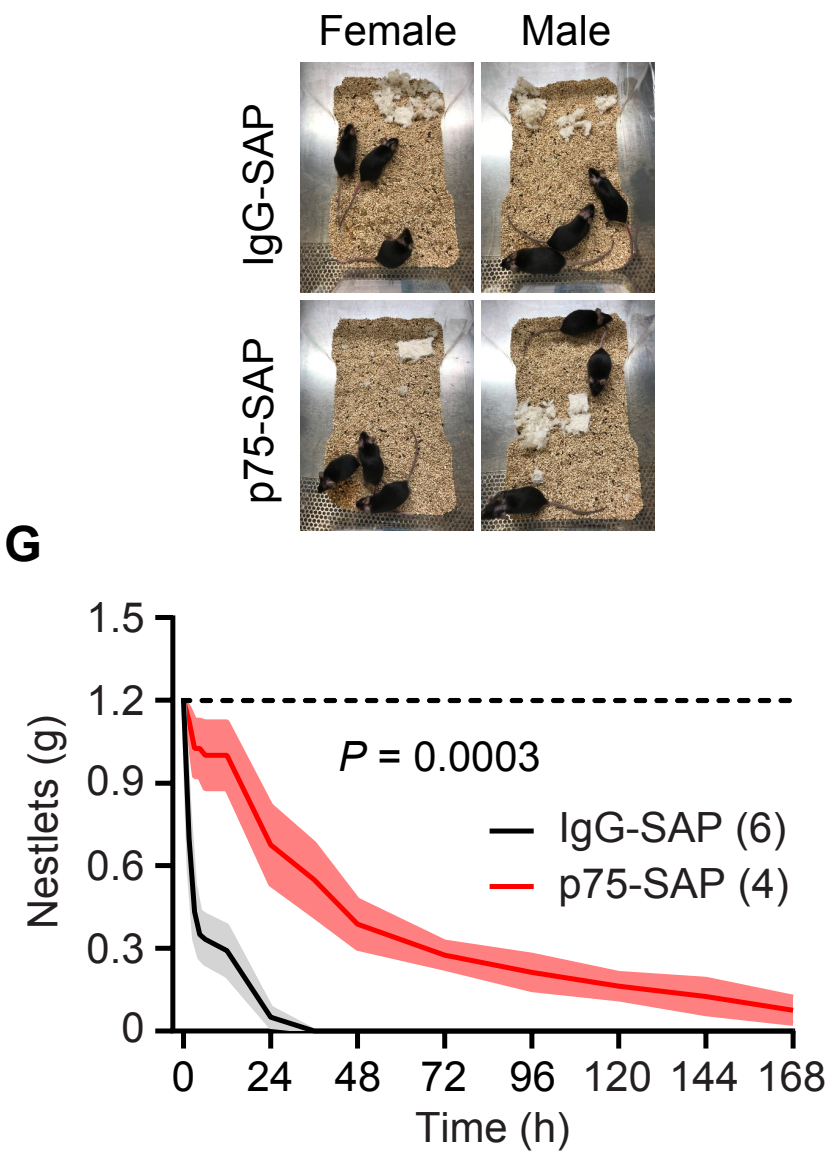

B

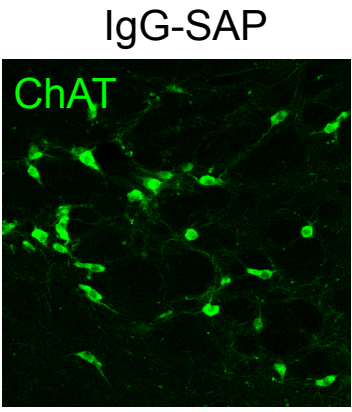

E

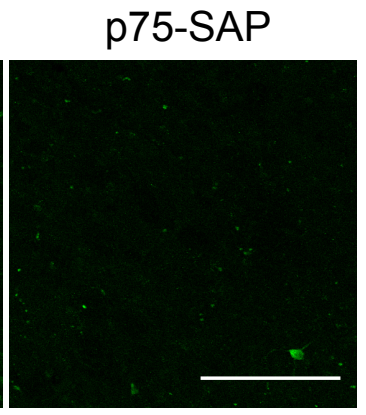

C

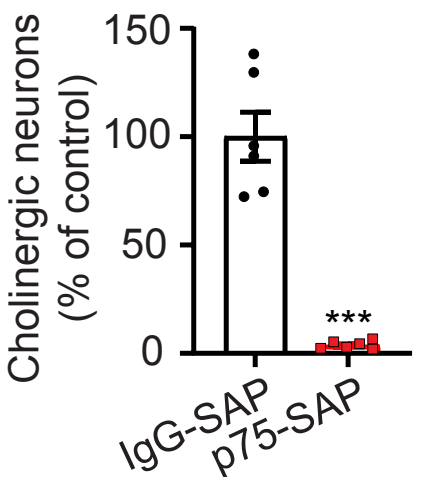

- Female IgG-SAP (4) - - . Male IgG-SAP (4)

$\rightarrow$ Female p75-SAP (4) - . Male p75-SAP (4)

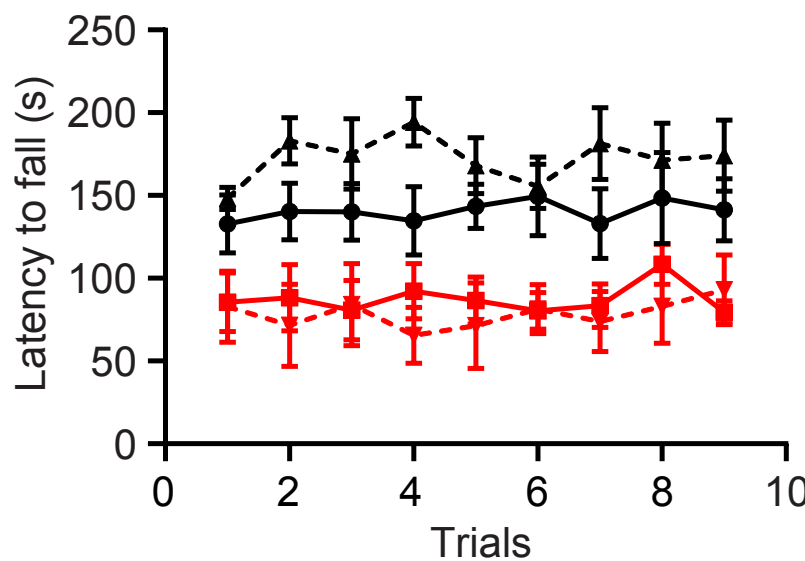

H

Recessed
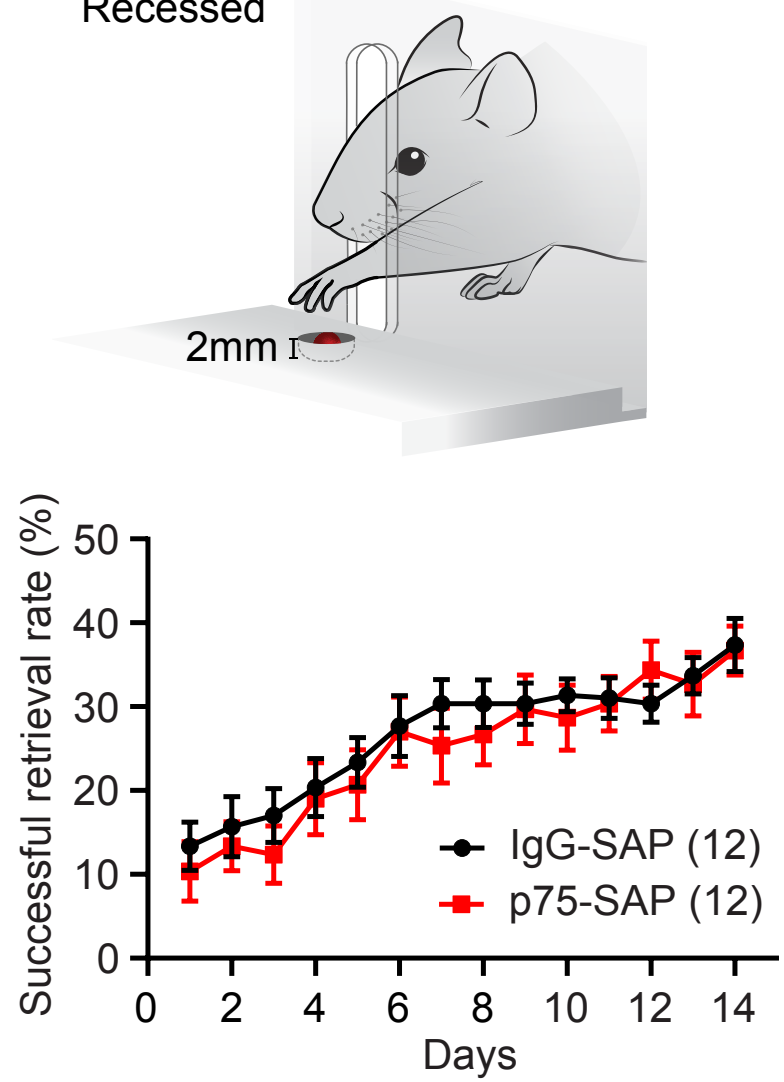
bioRxiv preprint doi: https://doi.org/10.1101/2021.04.24.441273; this version posted April 24, 2021. The copyright holder for this preprint (which was not certified by peer review) is the author/funder, who has granted bioRxiv a license to display the preprint in perpetuity. It is made

A

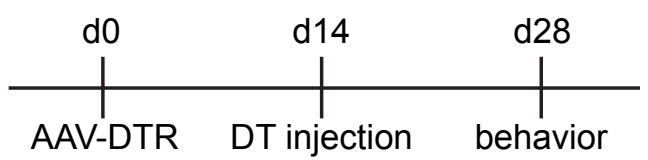

AAV-control

\section{AAV-DJ/8-FLEX-DTR-EYFP}

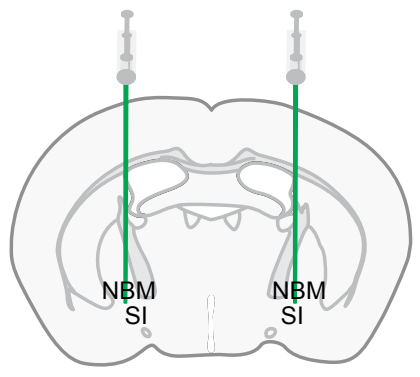

C

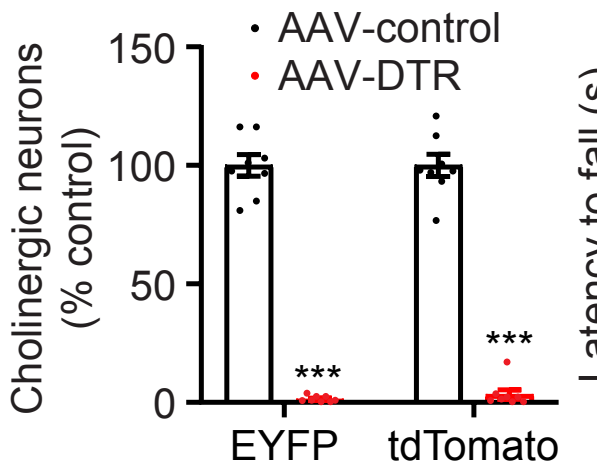

D

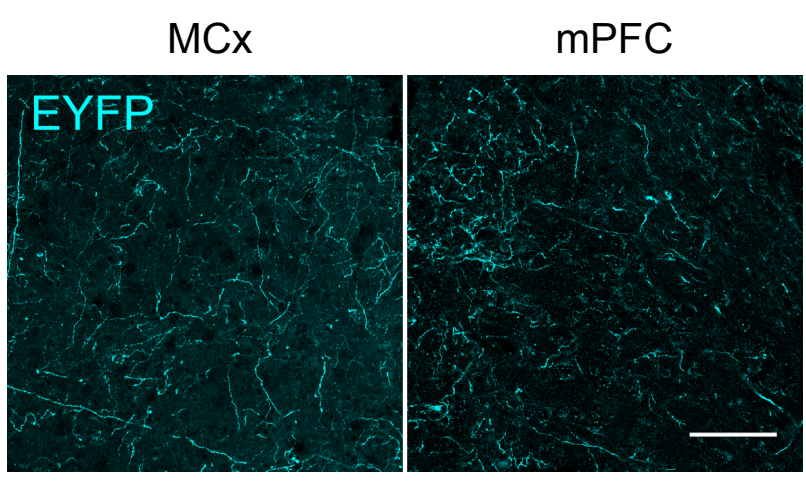

B

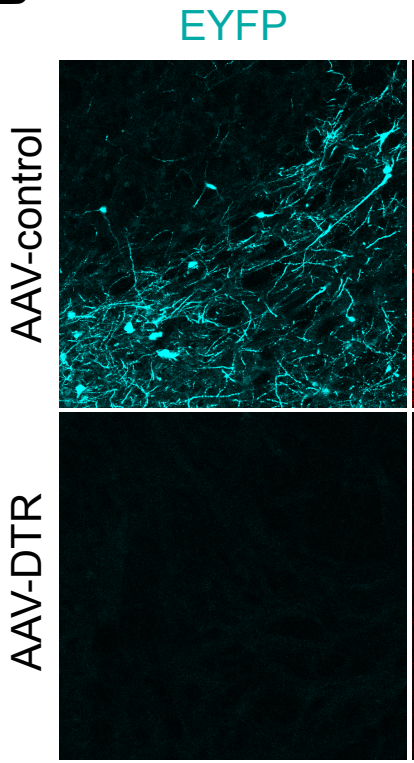

tdTomato
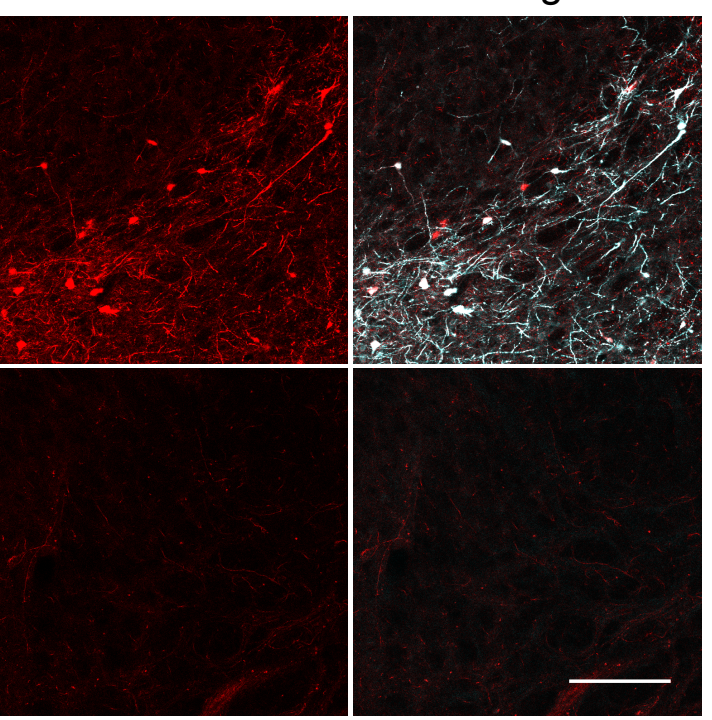

F
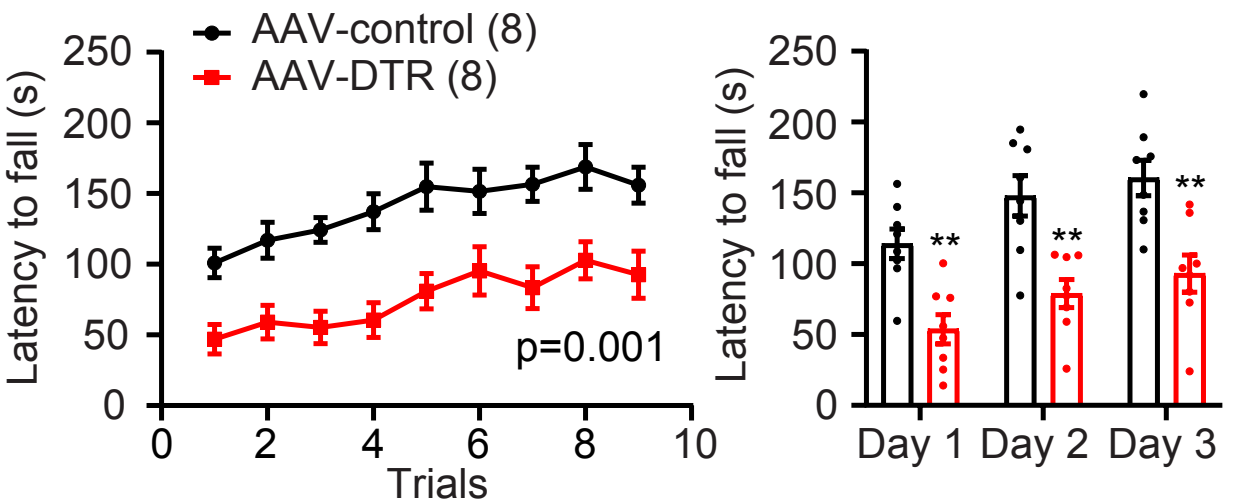

G

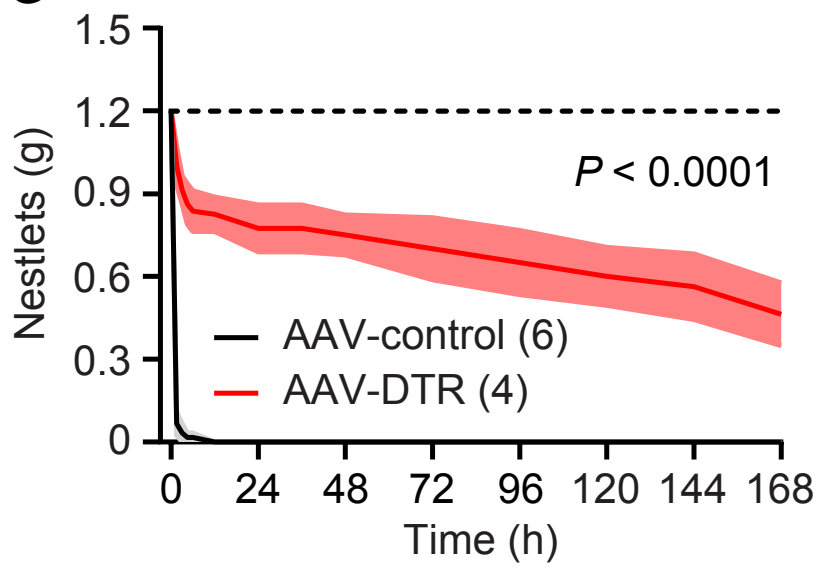


A

AAV8-DIO-mCherry/hM4Di

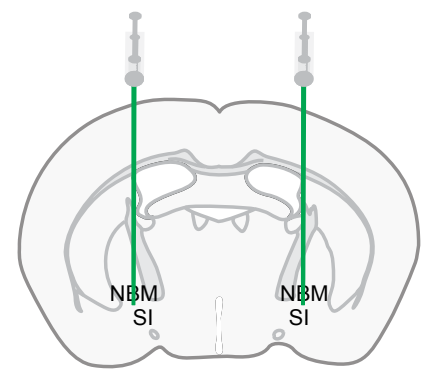

C

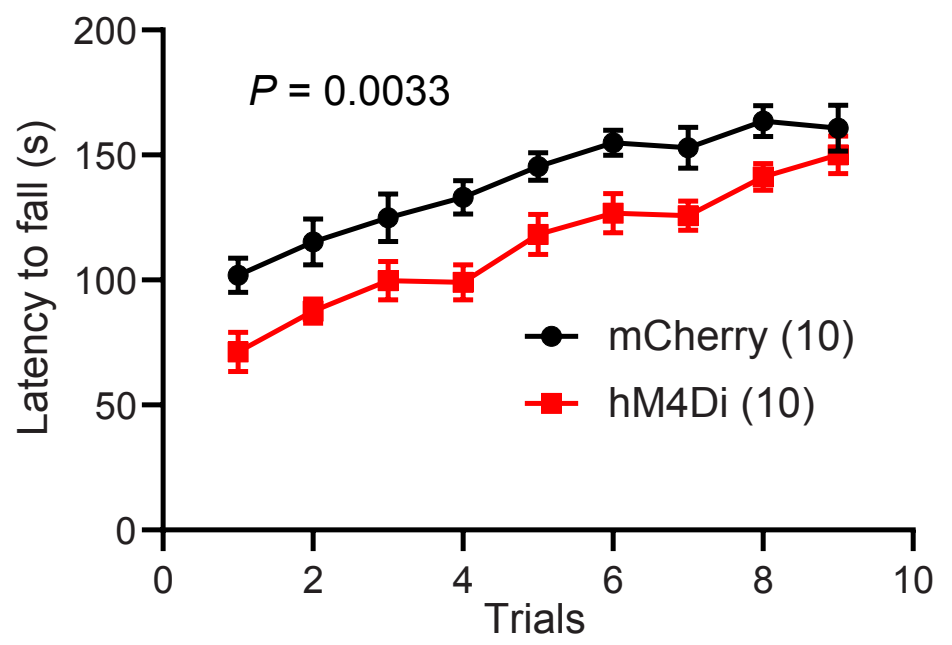

mCherry

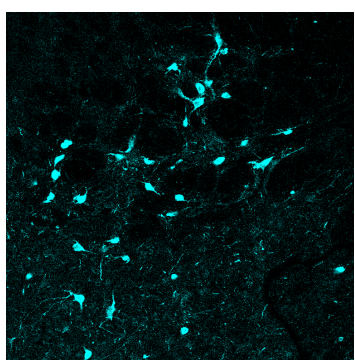

merge

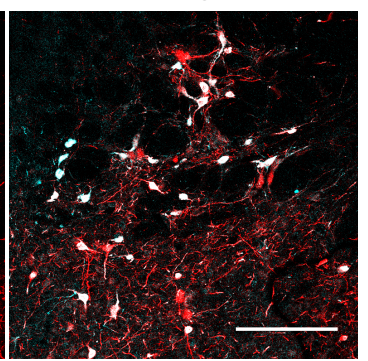

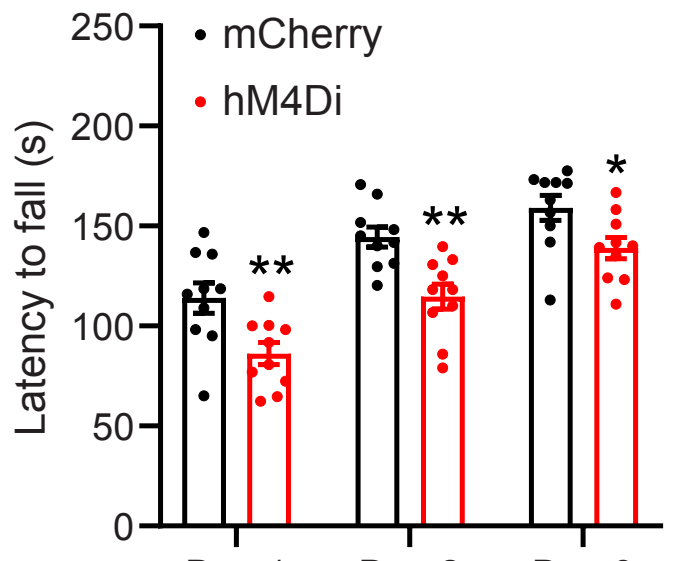

Day 1

Day 2

Day 3 
bioRxiv preprint doi: https://doi.org/10.1101/2021.04.24.441273; this version posted April 24, 2021. The copyright holder for this preprint (which was not certified by peer review) is the author/funder, who has granted bioRxiv a license to display the preprint in perpetuity. It is made

A available under ${ }_{B}{ }^{C C-B Y}$-NC-ND 4.0 International license.

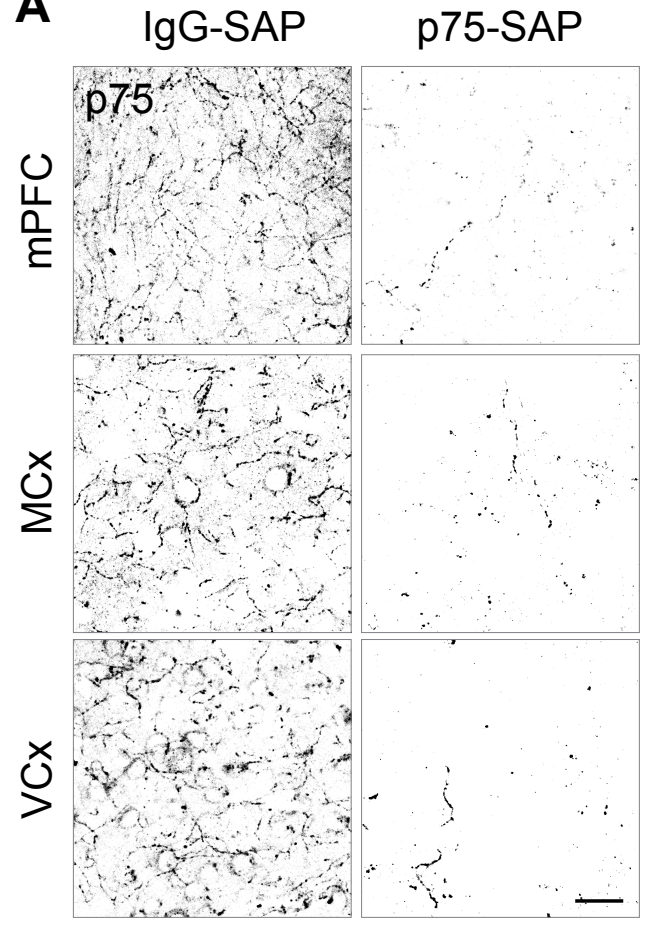

C

$\rightarrow$ IgG-SAP (16)

$\rightarrow$ p75-SAP mPFC (10)

$\rightarrow$ p75-SAP mPFC+MCx (10)

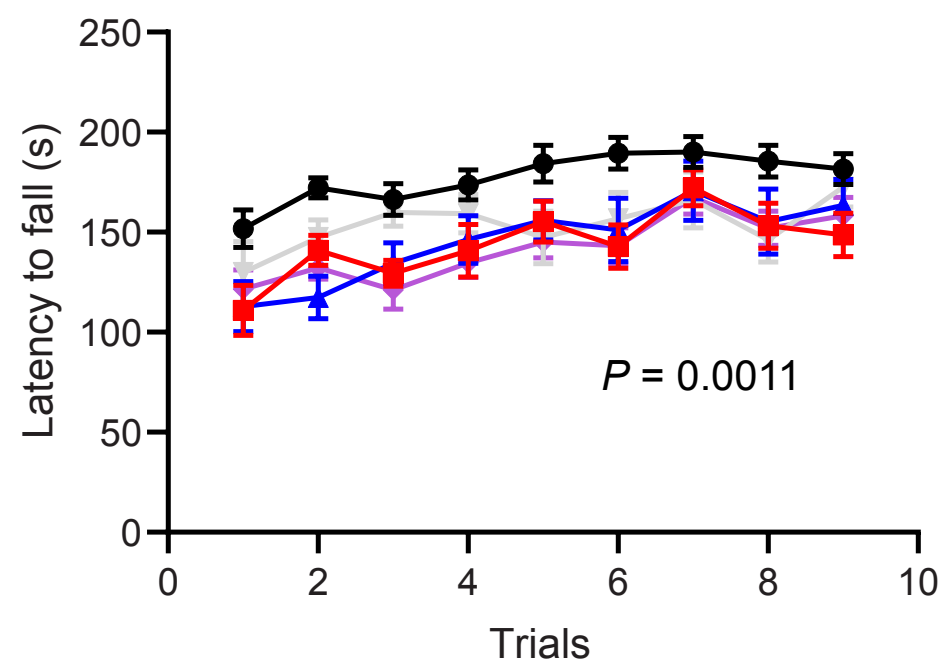

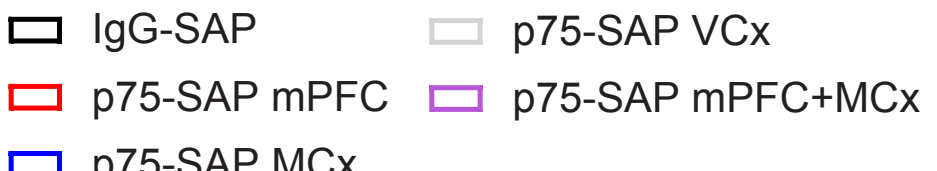

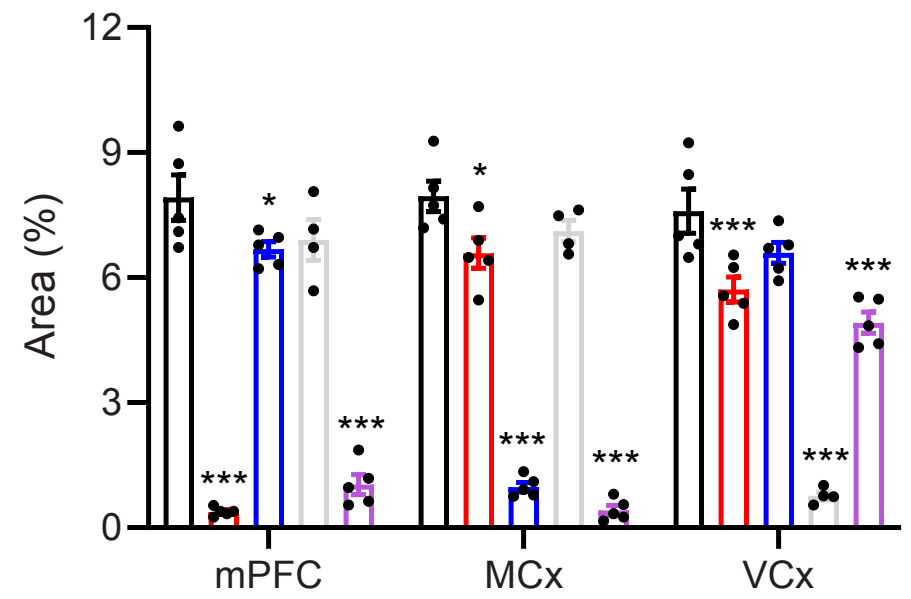

D 
bioRxiv preprint doi: https://doi.org/10.1101/2021.04.24.441273; this version posted April 24, 2021. The copyright holder for this preprint (which was not certified by peer review) is the author/funder, who has granted bioRxiv a license to display the preprint in perpetuity. It is made

A

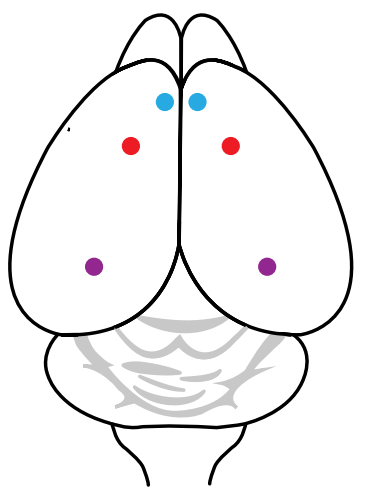

B

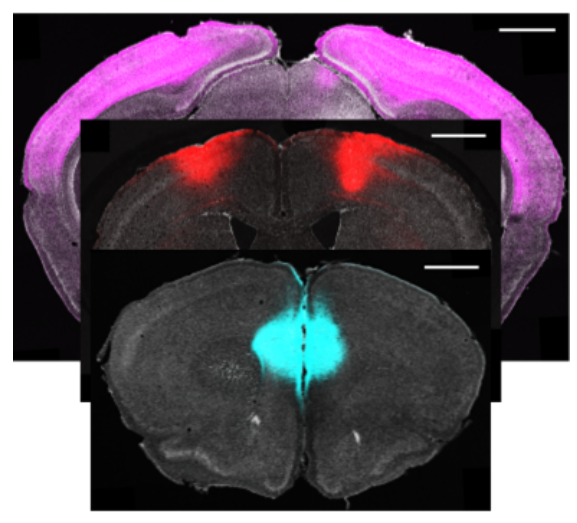

C $\circ$ ChAT-positive

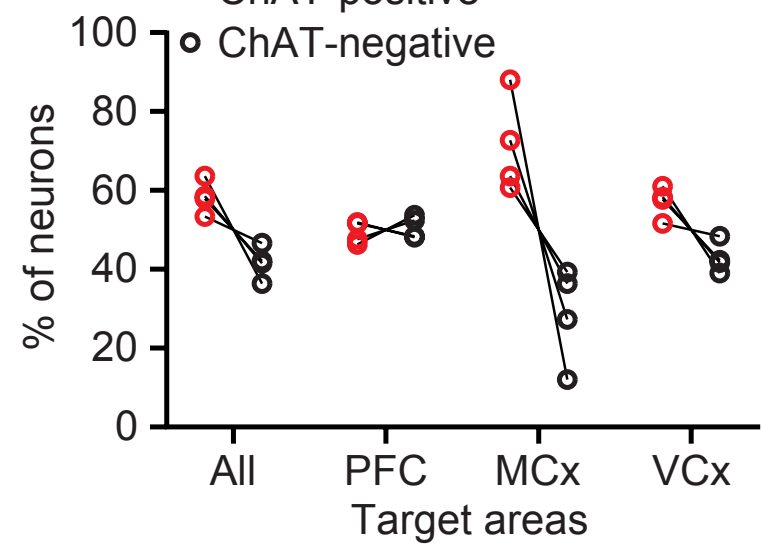

$\mathbf{E}$

\section{ChAT CTb488 CTb555 CTb647 Merge}

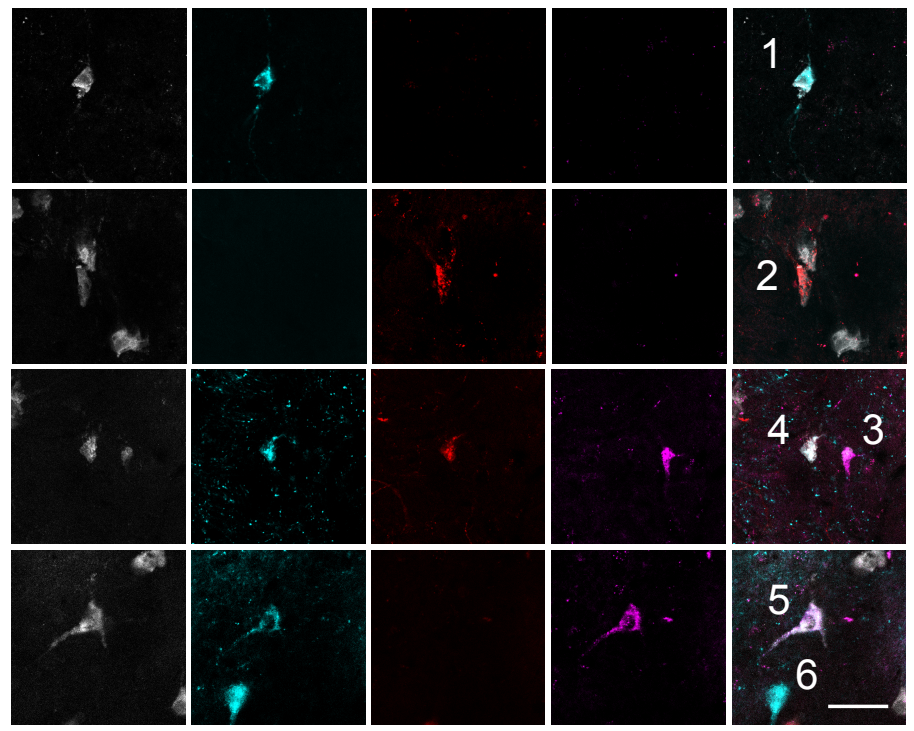

ChAT-positive neurons

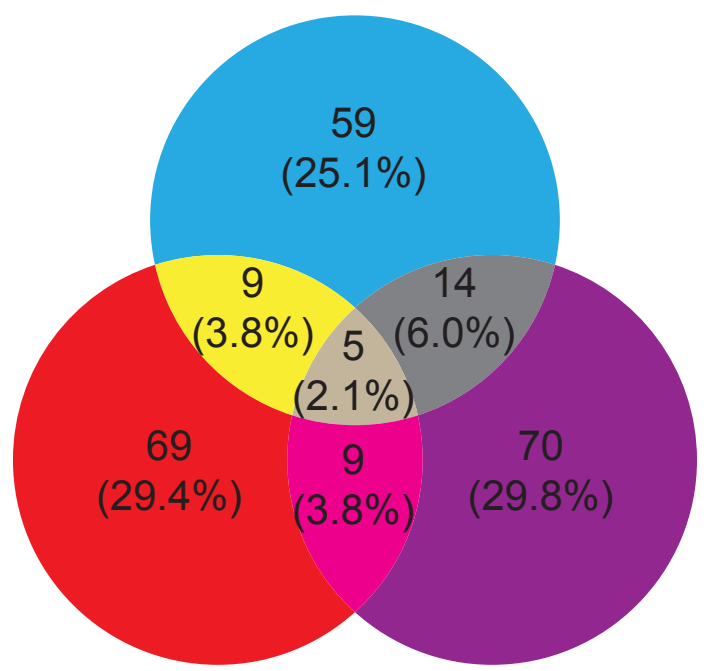


A

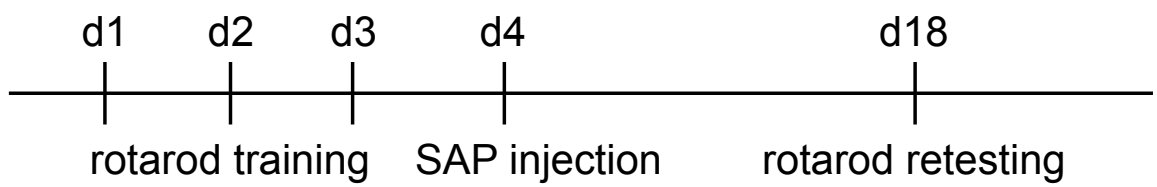

B

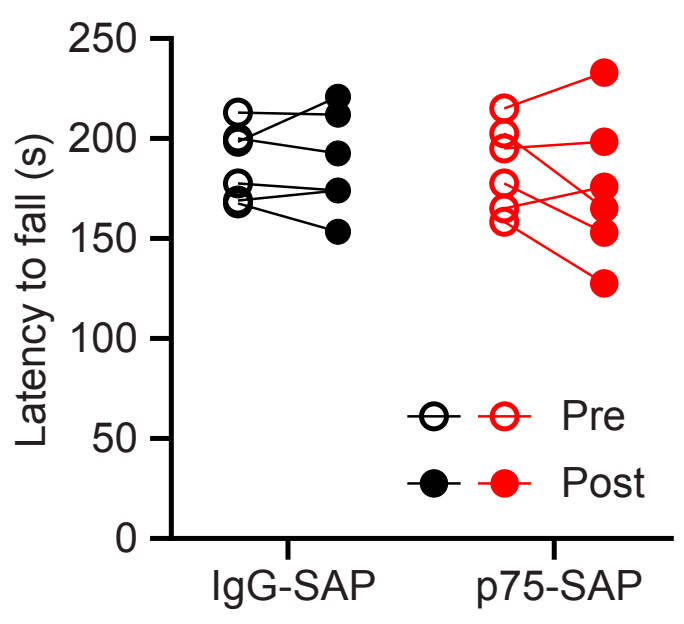

C

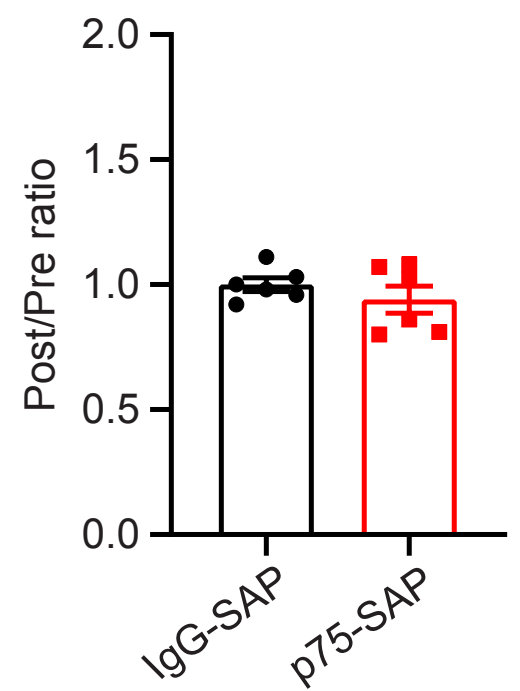

D

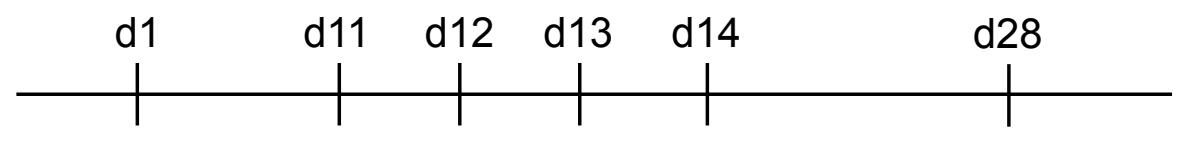

AAV-DTR rotarod training DT injection rotarod retesting AAV-control

E

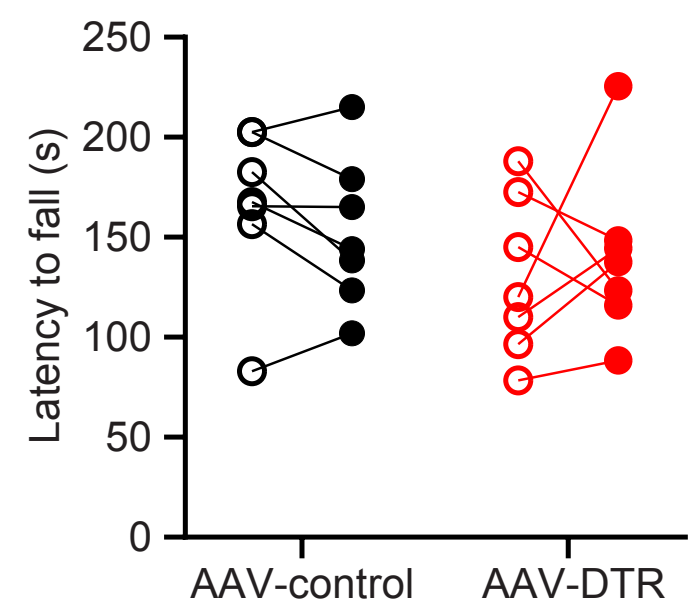

$\mathbf{F}$

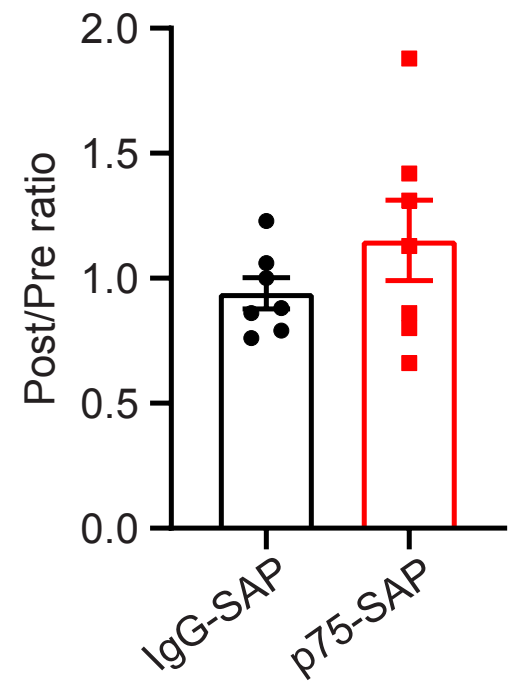


A
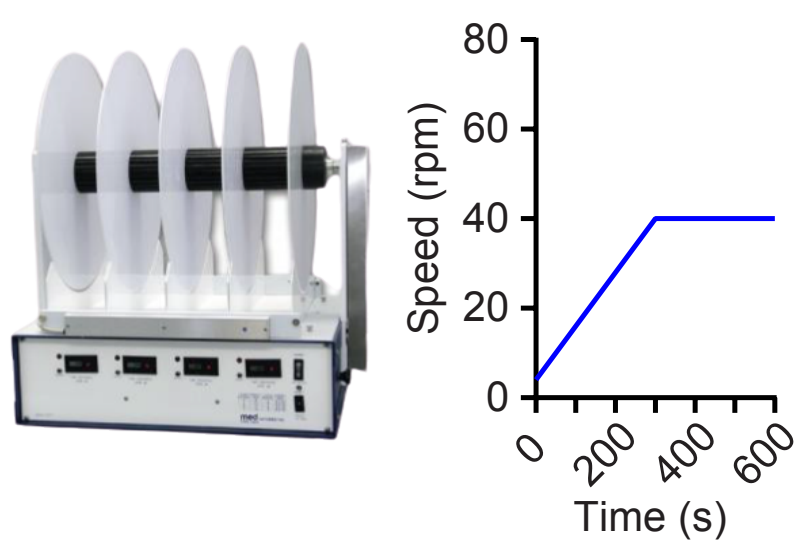

C

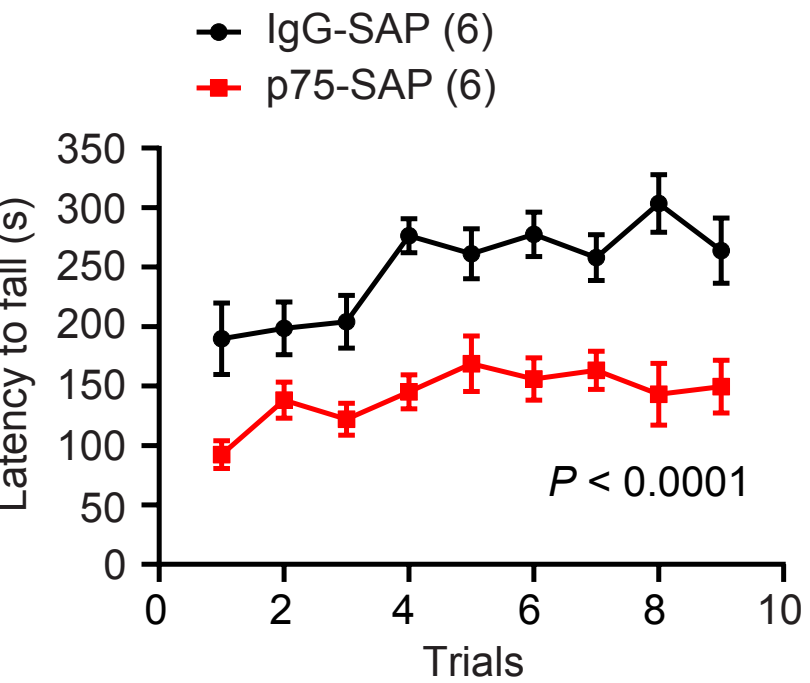

B
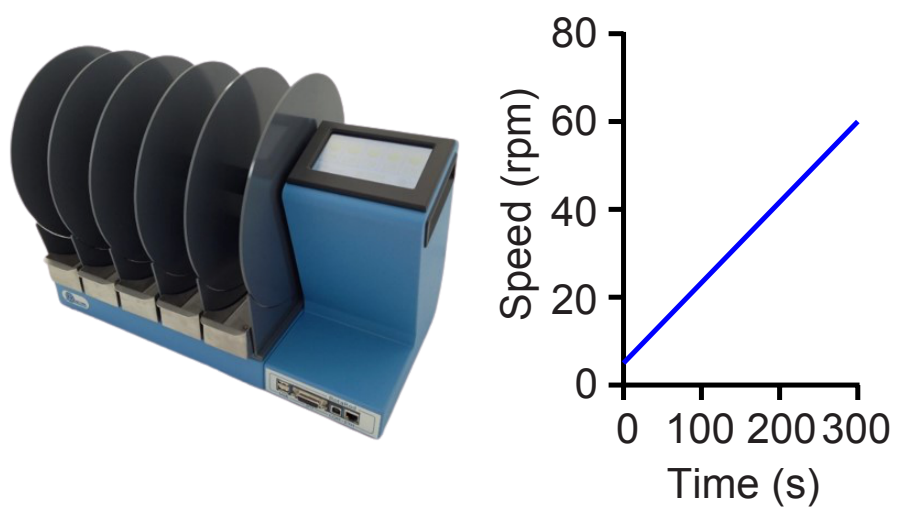

D

- - Female IgG-SAP (3) - -k. Male IgG-SAP (3)

$\rightarrow$ Female p75-SAP (3) - - . Male p75-SAP (3)

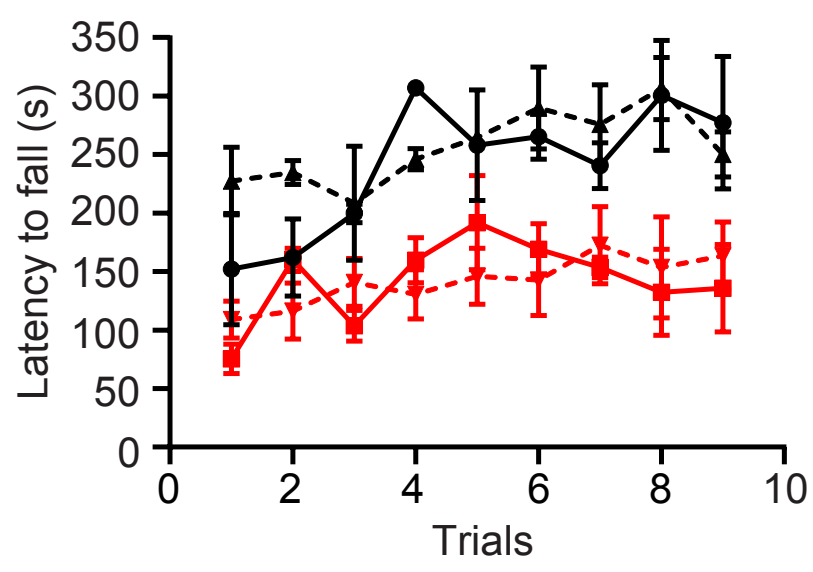



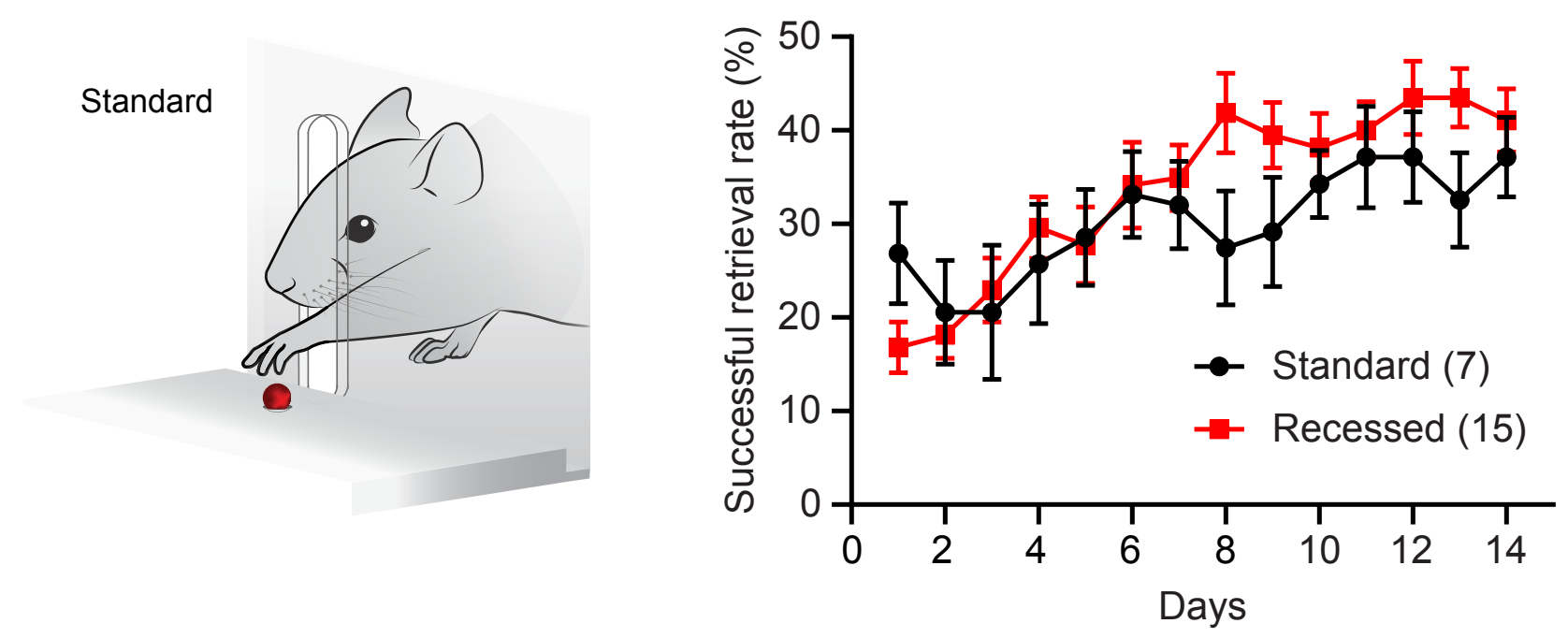

C

Standard

Learners

Non-learners

Recessed
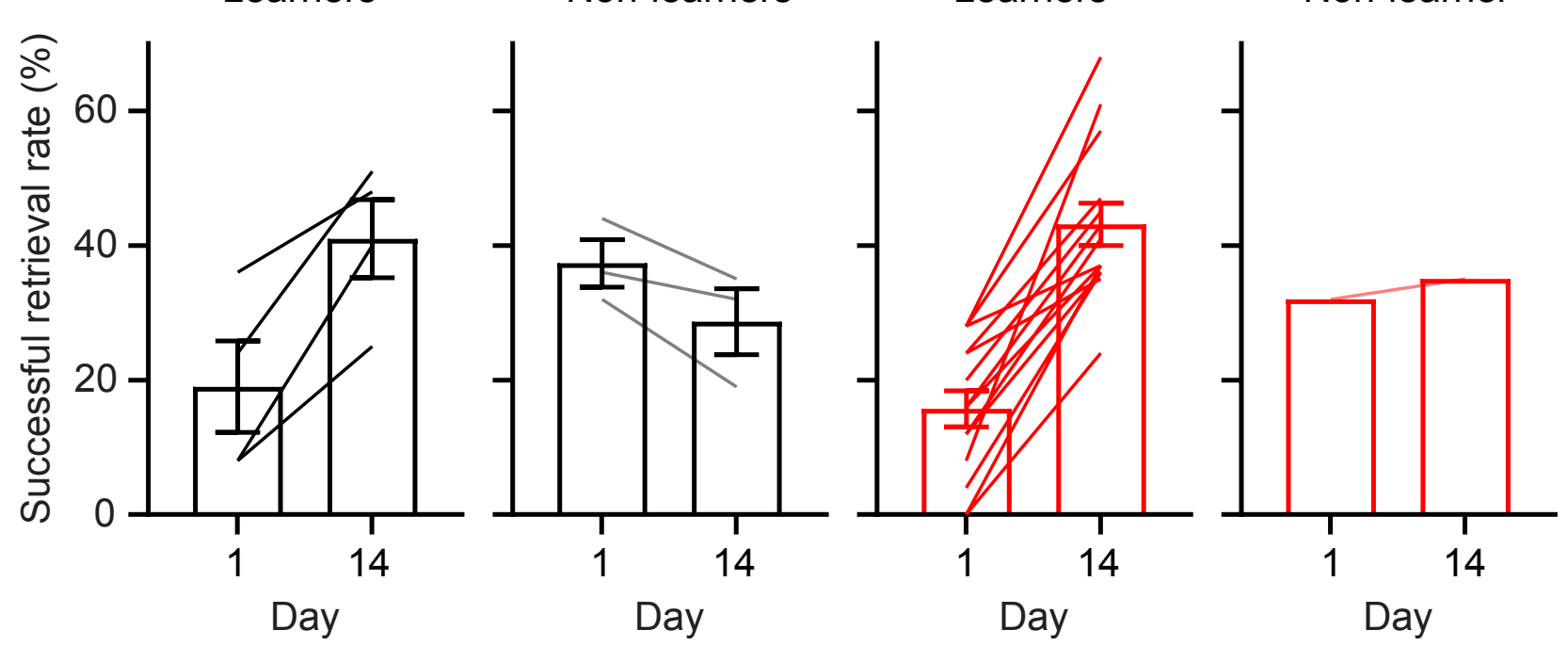

Non-learner

Learners 
bioRxiv preprint doi: https://doi.org/10.1101/2021.04.24.441273; this version posted April 24, 2021. The copyright holder for this preprint (which

A was not certified by peer review) is the author/funder, who has granted bioRxiv a license to display the preprint in perpetuity. It is made available undeBCC-BY-NC-ND 4.0 International license.

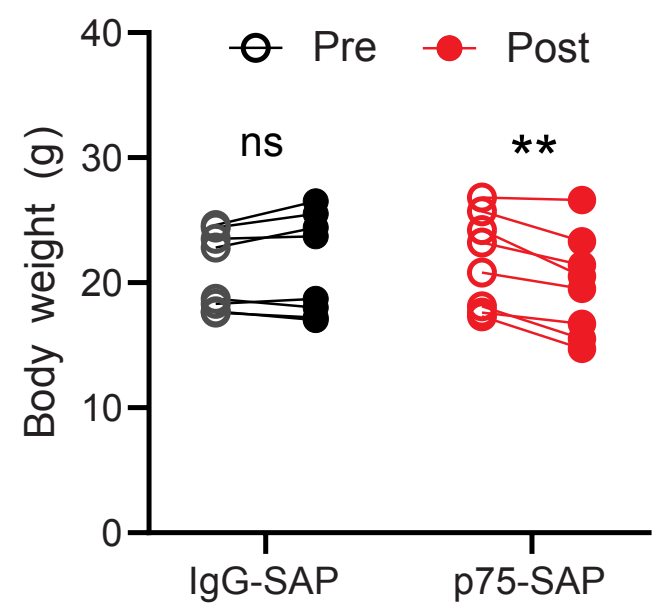

D
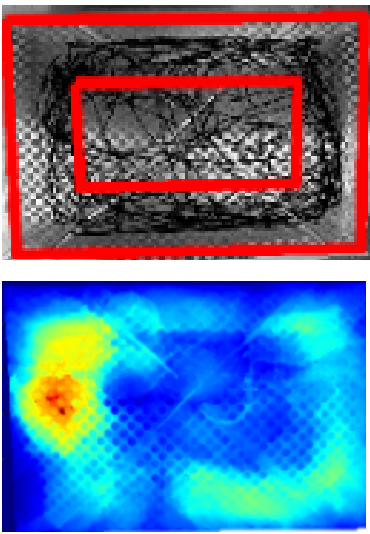

E

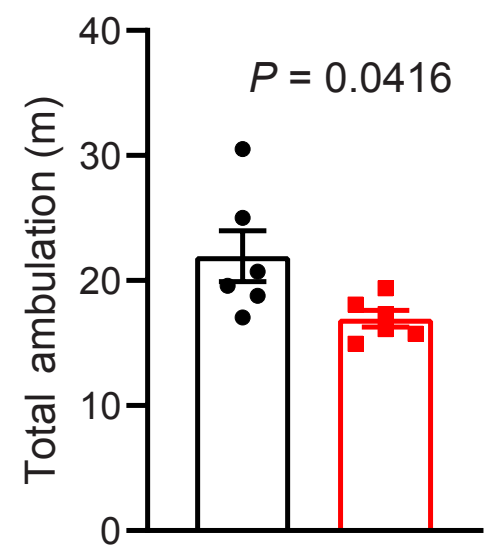

Grid hang test
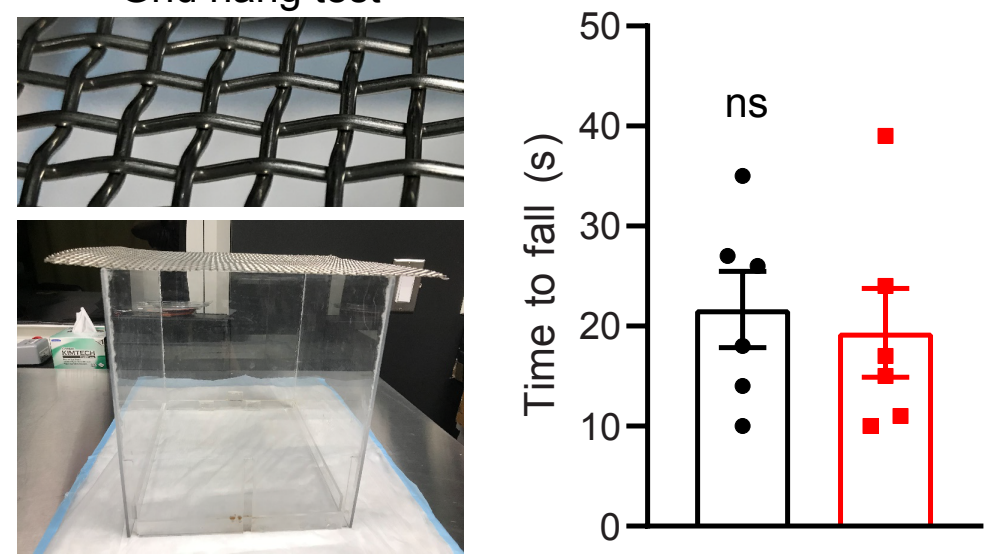

$\mathbf{F}$

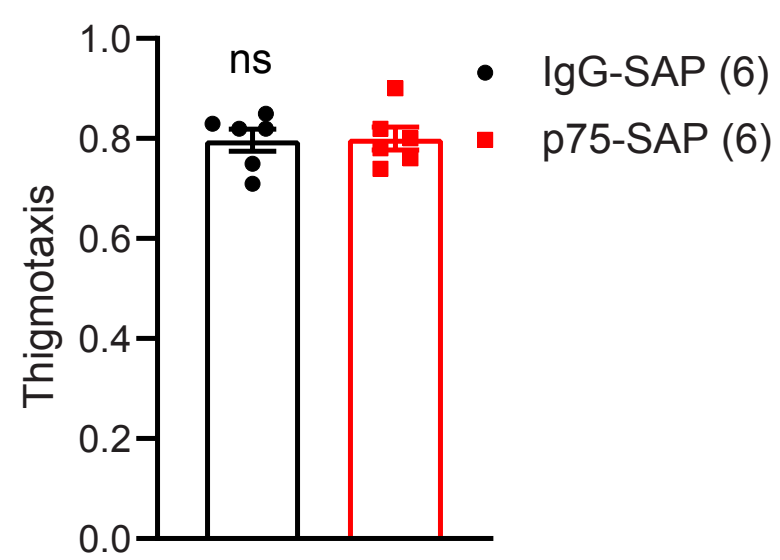


bioRxiv preprint doi: https://doi.org/10.1101/2021.04.24.441273; this version posted April 24, 2021. The copyright holder for this preprint (which A was not certified by peer review) is the author/funder, who has granted bioRxiv a license to display the preprint in perpetuity. It is made

Left: AAV-DJ8-control available under aCC-BY-NC-ND $\mathbf{B}$ International license.
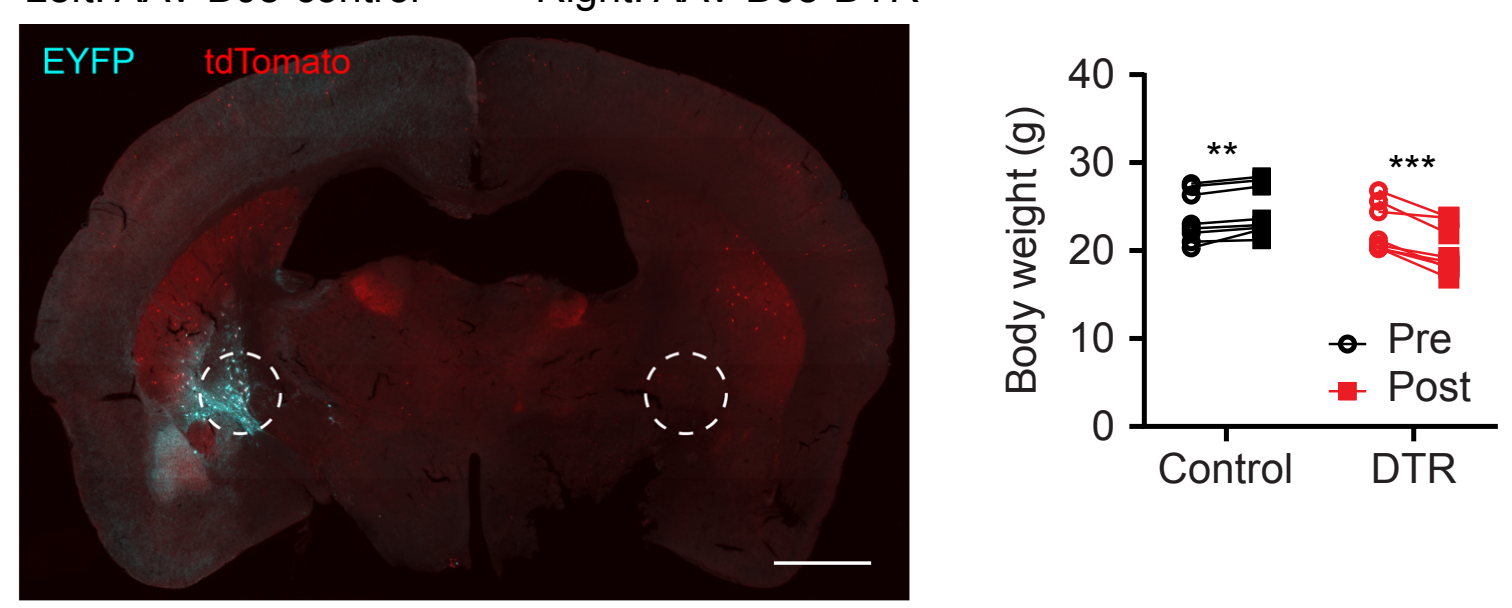

C

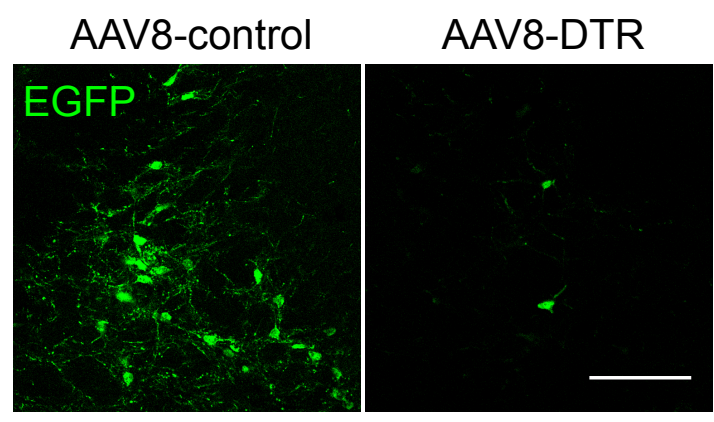

D

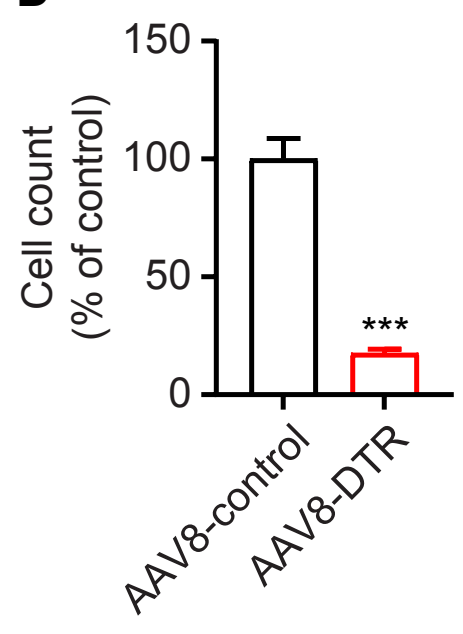

E

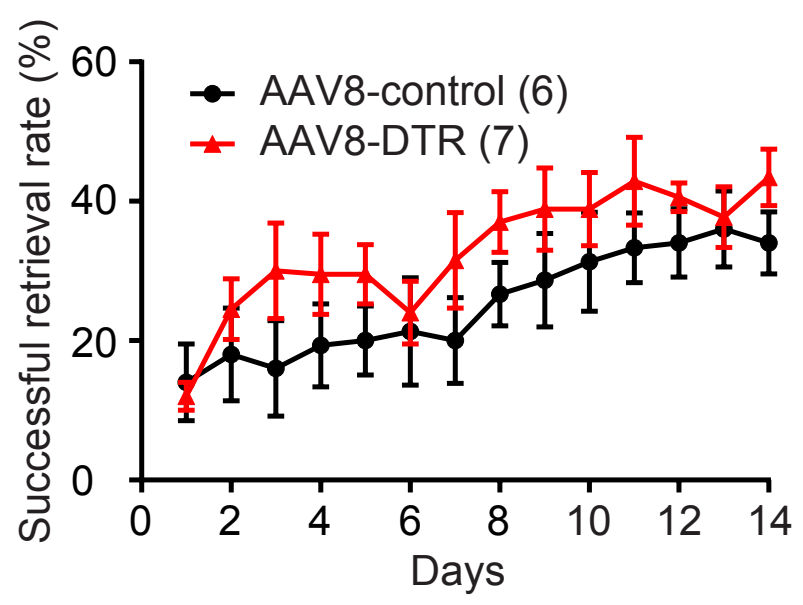


bioRxiv preprint doi: https://doi.org/10.1101/2021.04.24.441273; this version posted April 24, 2021. The copyright holder for this preprint (which was not certified by peer review) is the author/funder, who has granted bioRxiv a license to display the preprint in perpetuity. It is made available under aCC-BY-NC-ND 4.0 International license.

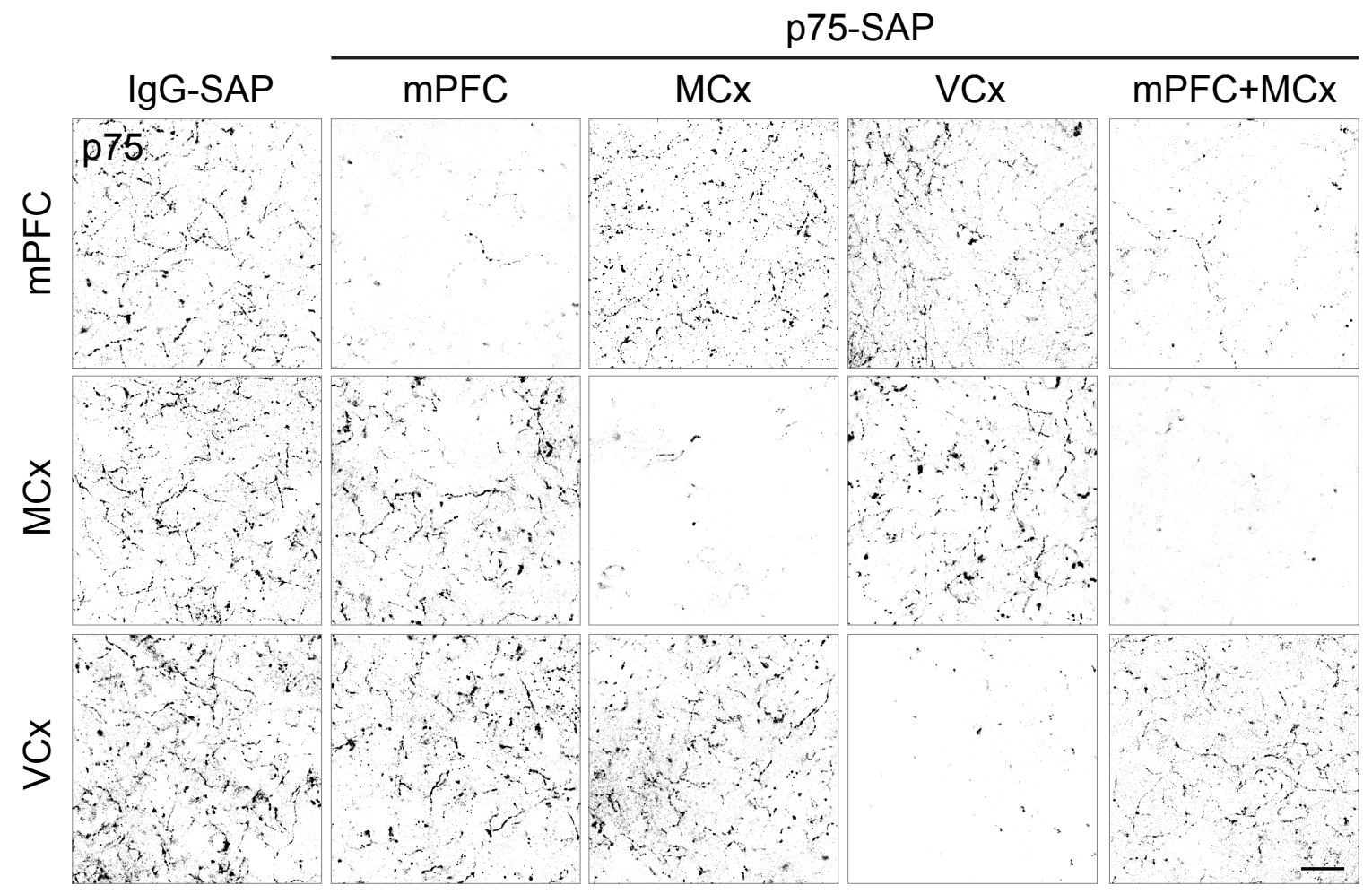


bioRxiv preprint doi: https://doi.org/10.1101/2021.04.24.441273; this version posted April 24, 2021. The copyright holder for this preprint (which was not certified by peer review) is the author/funder, who has granted bioRxiv a license to display the preprint in perpetuity. It is made

A available under aCC-BY-NC-ND 4.0 International license.

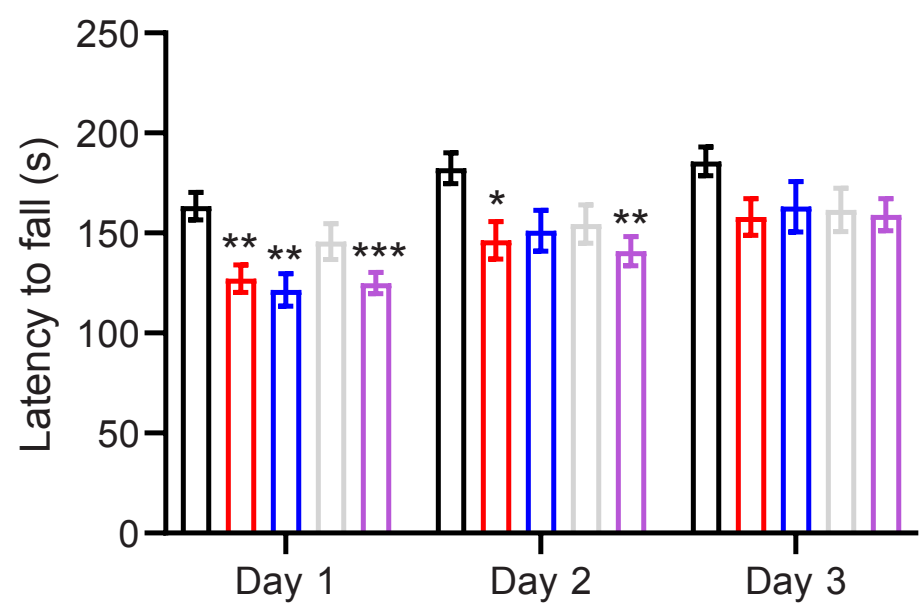

B

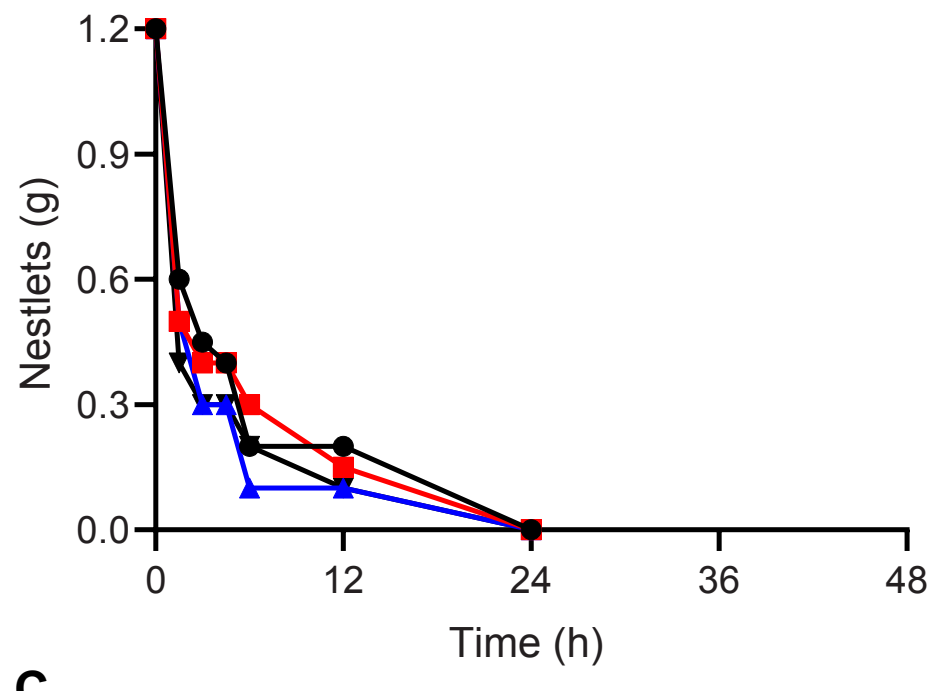

C

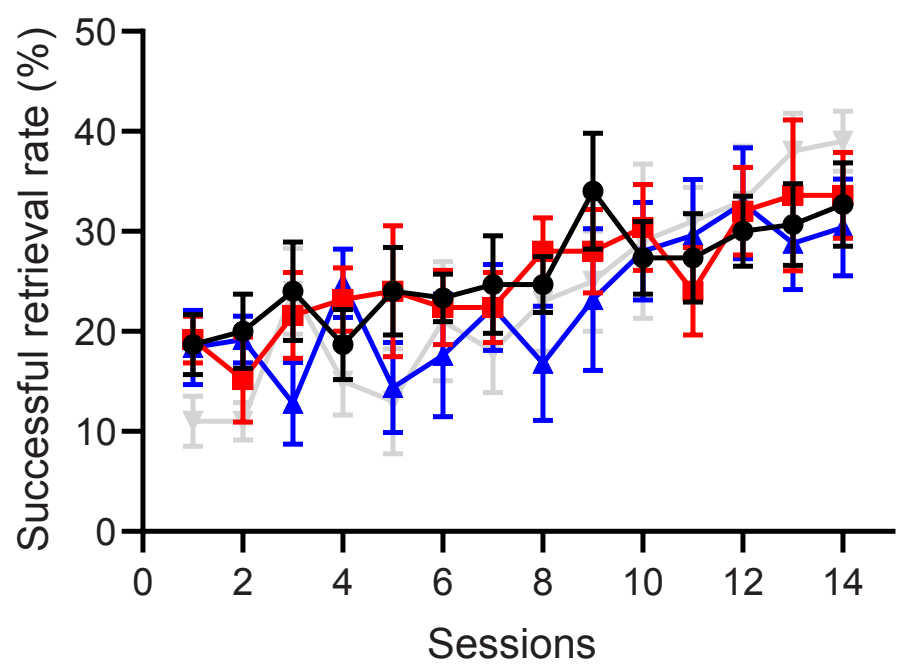

$\square \operatorname{lgG}-S A P(16)$

$\square$ p75-SAP mPFC (10)

$\square$ p75-SAP MCx (10)

p75-SAP VCx (9)

p75-SAP mPFC+MCx (10)

$$
\begin{aligned}
& \rightarrow \text { IgG-SAP } \\
& - \text { p75-SAP mPFC } \\
& \neq \text { p75-SAP MCx } \\
& \rightarrow \text { p75-SAP VCx }
\end{aligned}
$$

$$
\begin{aligned}
& \rightarrow \text { IgG-SAP (6) } \\
& - \text { p75-SAP mPFC (5) } \\
& + \text { P75-SAP MCx (5) } \\
& + \text { p75-SAP VCx (4) }
\end{aligned}
$$

